\title{
Indexation and Normalization Modeling of Natural Gas Endowment
}

\author{
Roberto F. Aguilera ${ }^{1}$, Roberto Aguilera ${ }^{2}$
}

\section{Abstract}

A novel modeling method is presented for indexing and normalizing natural gas endowments of petroleum provinces. The approach is demonstrated with data from Canada, the Unites States, and Latin American and Caribbean (LAC) countries. A variable shape distribution model (VSD) is used to fit the conventional natural gas endowment published by the United States Geological Survey (USGS) for 29 provinces in LAC countries and 85 provinces in Canada and the United States. This data is indexed and normalized to generate curves showing number of provinces versus normalized endowments. Results are compared with normalized endowments from provinces in other regions around the world, including Europe, Asia Pacific, the Middle East, North Africa, and the former Soviet Union (FSU). The comparison gives the method predictive power for estimating the natural gas endowment, particularly in LAC provinces, that at present have little exploration activity. Of particular importance is the fact that all the curves of the various regions display a generally concave pattern throughout. The exception is the LAC curve, which displays the shape of an inverted "S" and has a distinct convex pattern at the largest gas endowment volumes. This comparison suggests there is potentially a large volume of natural gas in the region that has not been considered in previous studies.

Keywords: Natural gas; Indexation; Normalization; Modeling; Size distribution; VSD model; Canada; United States; LAC countries

\section{Introduction}

There is a significant endowment of hydrocarbons in North, Central and South America, which given enough research and development, may help satisfy the energy needs of these regions for several decades to come (Aguilera and Aguilera, 2010). The data used in Aguilera and Aguilera (2010) was published originally by the USGS (1995, 2000), the Minerals Management Service (MMS, 1996) and Klett et al. (1997).

\footnotetext{
${ }^{1}$ Corresponding Author. Curtin University, Centre for Research in Energy and Minerals Economics (CREME), GPO Box 1987, Perth, Australia, 6845. Email: r.aguilera@curtin.edu.au, Phone: 618-9266-9137

${ }^{2}$ University of Calgary, Chemical and Petroleum Engineering Department, Schulich School of Engineering, 2500 University Drive NW, Calgary, Canada, T2N-1N4. Email: r.aguilera@ucalgary.ca
} 
The present study concentrates on indexation and normalization modeling of the conventional natural gas endowment in Canada, the United States, and LAC. It then compares these results to normalized curves from other regions around the world in order to gain insights about regions with underestimated endowments. The paper does not include unconventional sources of gas such as tight gas, shale gas or coal bed methane. It uses the definitions of the USGS (2000) study (see Table 1). Each of the USGS definitions that deal with volumes can be applied to petroleum or to oil, natural gas and natural gas liquids (NGL) separately. Conventional petroleum is the sum of oil with more than 15 degrees API, gas and NGL.

Figure 1 is a diagram explaining the relation between some of the definitions that are most relevant to this paper. Both known volumes and future volumes are used to develop the variable shape distribution (VSD) graphs for Canada and the United States, LAC, Europe, Asia Pacific, Middle East and North Africa, and the FSU. Note that North America, as defined by the USGS, includes Canada, the United States and Mexico. The LAC countries presented in our study include Mexico, while there is a separate evaluation for the Unites States and Canada.

The shape variation is one of the unique and important points of the methodology used in this paper. Similar approaches have been used in the past, but all of those methods incorporate constant shapes. Based on our observation of global USGS data, the constant shape technique is not as reasonable as the variable shape method proposed in this paper. In section 5 (VSD Validation), we explain the VSD methodology, highlight its advantages and demonstrate that the VSD - in addition to handling variable shapes also encompasses the assumption of constant shapes considered in previous methods. In efforts to align the USGS (2000) definitions with those developed by the SPE/WPC/AAPG/SPEE/SEG (2011) in the Petroleum Resources Management System (PRMS), we have compared terminology as shown in Fig. 2. The comparison applies to classes associated with the chance of commerciality.

There is always uncertainty in petroleum province size estimation because of data shortages in the oil and gas industry. As such, there are uncertainty levels inherent in the USGS reports. Generally, the larger the reservoir, the larger the amount of available data, thus reducing the uncertainty associated with the largest province (which is critical for the indexations proposed in this paper). The USGS publicizes the mean values, which are the volumes used in this paper as a starting point. These uncertainties extend necessarily to the VSD model. However, once the mean values of the USGS are accepted as reasonable, the results of the VSD work well. This statement is supported by (1) coefficients of determination $\left(\mathrm{R}^{2}\right)$ that are generally greater than 0.98 and (2) 
VSD-estimated endowments that are very similar to those published by the USGS. The core of the USGS procedure is the use of high quality geologic evaluations, specialized techniques like reservoir-simulation modeling, discovery-process modeling, and application of geologic and production analogs. Probability distributions are also used in the USGS study to account for the uncertainty associated with estimating undiscovered volumes.

\section{Study Area}

Figure 3 shows a map that includes Canada, the United States, and LAC - the primary study areas in this paper. The secondary study areas, included for comparison purposes, are Europe, Asia Pacific, the Middle East, North Africa, and the FSU. The USGS province codes, names and gas endowments of petroleum provinces in the United States and Canada are presented in columns 1,2 and 4 of Table 2, respectively. The same information for LAC petroleum provinces is presented in Table 3. There are a total of 85 petroleum provinces assessed by the USGS for Canada and the United states (in addition to seven provinces showing zero gas endowment and one province, Salina Basin, with less than 100 billion cubic feet of gas [BCFG]). For LAC countries, there are 30 petroleum provinces assessed by the USGS (but no data is available for province 5310, Sierra Madre de Chiapas-Peten Foldbelt). As a result, our study includes only 85 petroleum provinces for Canada and the United States and 29 petroleum provinces in LAC countries. The tables include the mean conventional gas endowment (column 4) for each province as reported by the USGS, the normalized gas endowment (column 5), the calculated endowment (column 6) and the calculated normalized endowment (column7). The mean conventional gas endowment includes undiscovered volumes estimated by the USGS. It does not include reserve growth or unconventional sources of gas.

The actual and calculated data are also presented in Fig. 4 for Canada and the United States, and Fig. 5 for LAC countries, as log$\log$ cross plots of the cumulative number of provinces in the abscissa versus the normalized gas endowment in the ordinate. The black diamonds represent natural gas endowments published by the USGS. The solid blue continuous line corresponds to the endowments calculated with the VSD model. The "variable" part of the VSD name is meant to distinguish it from the crossplots utilized in fractal analysis, which is based on a "constant" shape (i.e. a straight line on log-log coordinates). The straight lines are not observed on the crossplots of hydrocarbon endowments presented in this paper or those prepared previously by Aguilera (2006) and Aguilera et al. (2009). The comparison of the USGS data and VSD modeling results is good, as corroborated by visual 
inspection and a coefficient of determination $\left(\mathrm{R}^{2}\right)$ equal to 0.99. However, a comparison of the VSD curves with the USGS (1995, 2000), MMS (1996) and Klett et al. (1997) endowments show that there are some differences at certain levels. The differences are accounted for in Figs. 4 and 5 by plotting 20\% horizontal error bars. Note that in nearly all cases, the $20 \%$ error bars exceed the difference between the USGS and VSD calculated endowments.

Table 2 and Fig. 4 show that the USGS endowment for Canada and the United States in 85 petroleum provinces is 1687 trillion cubic feet of gas (TCFG). This compares well with 1684 TCFG estimated by the VSD model. Table $\mathbf{3}$ and Fig. $\mathbf{5}$ show that the USGS endowment for LAC in 29 petroleum provinces is 857 TCFG. This too compares well with 855 TCFG estimated by the VSD model. Figure 4 also includes a VSD curve (magenta squares) which predicts the endowment for all 172 petroleum provinces recognized by the USGS to exist in Canada and the United States. The estimated endowment is equal to 1,921 TCFG. The predictive power of the VSD is good as shown in section 5 and in previous studies by Aguilera (2006) and Aguilera et al. (2009). Figure 5 accounts for 128 petroleum provinces recognized by the USGS to exist in LAC countries. In this case, the VSD estimated endowment is 1487 TCFG. The methods used to generate, index and normalize these data are discussed next.

\section{Variable Shape Distribution model (VSD)}

The methodology used to develop the VSD curves shown in Figs. 4 and 5 has been published previously in the literature (Aguilera, 2006; Aguilera et al., 2009) and therefore is not repeated here. However, for completeness and to facilitate the flow of the paper, the VSD modeling equation is shown below:

$$
\min _{\left\{V_{x}, a_{p}, V_{s}, \psi, S\right\}} \sum_{i=1}^{n}\left(V_{i}-\hat{V}_{i}\right)^{2}
$$

Subject to: 


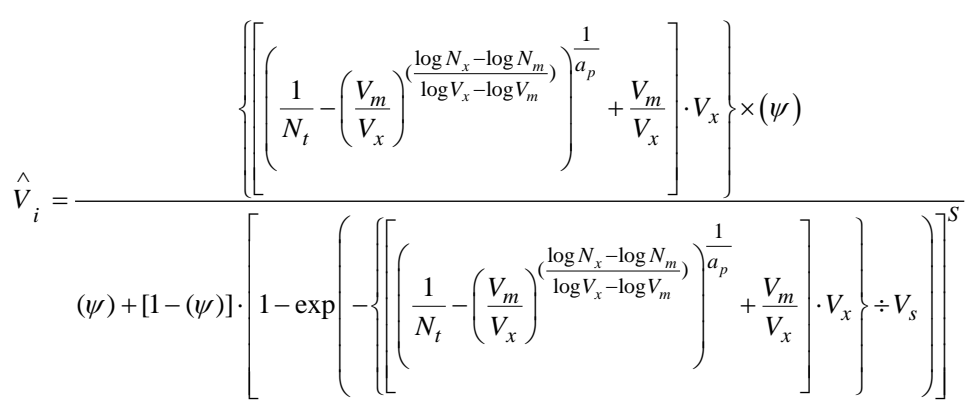

where $a_{p}=$ absolute value of slope of straight line approximated from USGS sample points (same as absolute value of slope of Pareto distribution), $N_{m}=$ minimum number of USGS provinces, $N_{t}=$ cumulative number of provinces, $N_{x}=$ maximum number of provinces, $S=$ severity exponent that controls the steepness of the slope of the estimated VSD curve where it separates from the Pareto straight line (on the right tail of the distribution, typically near the largest volumes), $V_{m}=$ minimum USGS province volume , $V_{s}=$ separation parameter that controls the point at which the VSD curve begins to deviate from the Pareto straight line (generally

on the right tail of the distribution, near the largest volumes), $\hat{V}_{i}=$ estimated volume of a province, and $V_{x}=$ maximum volume given by the Pareto straight line (at $N_{m}=1$ ). The actual maximum volume could be larger, equal to, or smaller than $V_{x}, \psi=$ separation ratio that controls the amount of separation between the Pareto straight line and the estimated VSD curve (on the right tail of the distribution, near the largest volumes).

Table 4 shows five parameters that are estimated in the VSD equation: $V_{x}, a_{p}, V_{s}, \psi$, and $S$. These parameters are used to obtain the best possible fit of the USGS endowments for Canada and the United States (Fig. 4), LAC countries (Figs. 5, 7 and 8), and other normalized regions considered in this paper (Figs. 6(A) to $\mathbf{6}(\mathbf{G})$ ). Fundamentally, the question that must be asked is: does any of this make sense geologically? We think it does and this is supported in publications by researchers of the USGS (Drew, 1990, 1997; Drew et al., 1979, 1988; Crovelli and Barton, 1993; Barton and Scholz, 1995). They discovered that as exploration advanced in a given area, there was a continuous on-going discovery process that could best be modeled at the time with a power law distribution. Drew (1997) published a significant book with data from different areas (e.g. the Frio Strandplain play in Texas) explaining the importance of geology in the discovery process. His data showed that, as the number of discoveries increased, the mode of the reserves volumes was not constant; it was decreasing continuously. This led him to conclude that nature's parent population of petroleum resources followed a log-geometric distribution. The relation between log-geometric and Pareto distributions have been further discussed by Charpentier et al. (2007). Drew and his colleagues work was innovative, though an actual straight line (i.e. constant shape) on log-log coordinates was never reached. Essentially, they had to truncate their data based 
on economic considerations to obtain a straight line. This was one of the motivations for the development of our VSD model, where the line does not have to be truncated at any point and the volumes are constrained only by the number of USGS-defined provinces. The USGS Frio Strandplain data are used in section 5 to demonstrate the predictive power of the VSD.

\section{Indexation and Normalization Modeling}

In this study, the selected index is the natural gas volume of the province with the maximum endowment for each region (marked by asterisks in Tables 2 and 3). For example, the index for the USGS data shown in column 2 of Table 4 for LAC is equal to 221.679 TCFG. The index for the VSD-calculated LAC data is 222.040 TCFG, as shown in column 3 . The indexes for the other regions are also presented in Table 4. Normalization is carried out dividing the endowment of each petroleum province by the index (or maximum endowment) shown in Tables 2 and 3. Using the maximum endowment for this purpose is reasonable as our experience generally shows that the largest amounts of data are available for the largest reservoirs.

For comparison, Figs. 6(A) to 6(G) shows log-log crossplots of normalized endowments (or sizes of provinces) versus cumulative number of provinces for (A) LAC countries, (B) Canada and the United States, (C) Europe, (D) Asia Pacific, (E) FSU, (F) Middle East and North Africa, and $(\mathrm{G})$ the world. These graphs were developed following the same procedure described above. Visual inspection of the modeling shows that fits, vis-a-vis the USGS endowments, are always good with coefficients of determination $\left(\mathrm{R}^{2}\right)$ greater than 0.98 . Figure $6(\mathrm{~A})$ shows that in the case of LAC countries, the curve resembles an inverted ' $\mathrm{S}$ ' and has a convex shape at large normalized province sizes (or endowments). However, the USGS and VSD curves for other regions (curves in Figs. 6(B) to $6(G)$ ) generally have concave shapes throughout, with the possible exception of the FSU. Are the shape differences simply a coincidence or the result of significantly different geologic features? These are possibilities but they are unlikely. A plausible explanation is that the convex shape is the result of lack of research and exploration for natural gas in LAC countries. Our experience from working in all the LAC countries is that exploration and drilling density per unit area of sedimentary basins is very small, although to our knowledge this has not been published explicitly in the literature.

If the LAC curves had concave shapes like other regions around the world, the conclusion might be reached that LAC gas endowments could be larger, as shown by the VSD comparisons of concave and convex curves in Fig. 7. The data used to generate 
the concave curve in Fig. 7 is presented in the second LAC line of Table 4. The VSD model indicates that the concave curve assumption would add approximately 222 TCFG to the LAC endowment of 855 TCFG (from the convex shape) resulting in a grand total of 1,077 TCFG for the 29 provinces evaluated by the USGS in the region. Note that the concave line starts at the same maximum endowment (province 1) as the convex line in Fig. 7. The next data points (USGS provinces 2 to 12 in Table 3, represented by black diamonds in the convex line of Fig. 7) are replaced by VSD values calculated with control parameters shown in the second LAC line of Table 4. The idea of the concave curve is that it has to fit the maximum endowment as well as the smaller endowments in provinces 13 to 29 .

The same approach is used to generate Fig. 8, where the control parameters are identical except for the number of provinces that in this case are 128. The modeling shows that if the previously unassessed provinces in LAC countries are also taken into account, the concave assumption - presumably emanating from additional research and exploration - will increase the LAC endowment from 1,487 to 1,816 TCFG, a significant increase of 329 TCFG. The natural gas endowment in 172 provinces recognized by the USGS to exist in Canada and the United States is also large (1,921 TCFG, as shown in Fig. 4). Combining this with the LAC countries gives a total endowment of conventional natural gas for the Western Hemisphere equal to 3,777 TCFG that should lapse for several decades.

\section{VSD Validation}

The validation of the VSD model is demonstrated in this section with data published by the USGS (Drew, 1990, 1997; Crovelli and Barton, 1993; Barton and Scholz, 1995). All these authors assumed a constant shape (a Pareto-type straight line on log-log coordinates) in the evaluation of the Frio Strandplain play in Texas. The Frio Strandplain geology and depositional system have been summarized by Drew (1990, 1997). The original distribution of production data are presented in Fig. 9 for 3 different periods - through 1960, 1970 and 1985. Drew indicated that the parent population of oil and gas fields was log-geometric. His equivalent $\log -\log$ crossplot for the distribution to 1985 is shown in Fig. 10 (Crovelli and Barton, 1993). The graph truncates 7 data points corresponding to the smaller field sizes because of economic and exploration considerations. Crovelli and Barton (1993) stated that “a correlation coefficient of -0.97 indicates a good fit where -1.0 is a perfect negative fit. We propose that this is an appropriate though approximate fit to the data and that extrapolation of the line to smaller field sizes may be a valid basis for prediction of the ultimate undiscovered petroleum in field-size classes less than or equal to eleven." Although we agree that their fit is good for the 
truncated data set, we show it can be improved with the VSD model (even without truncating the data). Figure 11 contains data we digitized from a publication by Barton and Scholz (1995). This log-log plot is equivalent to the graph in Fig. 9. The data from Barton and Scholz are not truncated as in the case of Fig. 10. The following demonstrates a step by step application of the VSD:

1) Figure 12 shows the exact same USGS data represented by the lower curve in Fig. 11, but now we have added a continuous solid line that is calculated with the VSD model using the following control parameters: $a_{p}=0.61, N_{m}=1, N_{t}$ $=1$ to $315.01, N_{x}=315.01, S=2.3, V_{m}=0.032, V_{s}=3000, V_{x}=50,000, \psi=0.2$. Visual inspection shows a very good fit that is supported by a coefficient of determination $\left(R^{2}\right)$ equal to 0.98 .

2) Given the information in step 1, what would be the predicted theoretical distribution for 500 fields discovered in the Frio Strandplain play? The answer is provided by the VSD model in Fig. 13 using the exact same control parameters shown in step 1 . The only difference is the number of fields that are now $N_{x}=500.01$. Figure 14 brings in the actual data for the 500 fields as it occurred in 1970 (shown in Fig. 11). The predicted distribution is excellent with an $R^{2}$ equal to 0.98 .

3) Finally, what would be the predicted theoretical distribution for 700 fields discovered in the Frio Strandplain play? The answer is provided by the VSD model in Fig. 15 using the exact same control parameters shown in step 1. Again, the only difference is the number of fields that are now $N_{x}=700.01$. Figure 16 brings in the actual data for the 700 fields as it occurred in 1985 (shown in Fig. 11). The predicted distribution is excellent once more with an $R^{2}$ equal to 0.98 . The data in Fig. 16 are not truncated as in the case of Fig. 10, which eliminates 7 data points with the smallest field sizes. Even though we do not truncate a single data point in Fig. 16, the fits with the VSD curves are very good. This gives the methodology presented in this paper an imperfect yet remarkable predictive power.

The same types of fits have been obtained with the VSD model for several cases throughout the world. The method is not a panacea but is certainly a significant improvement for predicting the endowment of hydrocarbons in places where the geoscience and engineering data are limited. As discussed, the method is robust as it allows matching actual data when the shape of the curve on $\log$ - $\log$ coordinates is concave, convex, or straight. For the latter, $\psi=1.0, N_{x}$ is very large (for example, $N_{x}=1 \mathrm{E}+50$ ), and $V_{m}$ is very small (for example, $V_{m}=1 \mathrm{E}-50$ ). This is because Pareto's straight line can theoretically reach infinitesimally small sizes and an infinite number of fields. For this situation, the $V_{s}$ and $S$ values do not have any significance but they could remain as in this 
example $\left(V_{s}=3,000\right.$ and $\left.S=2.3\right)$. The values of $a_{p}$ and $V_{x}$ would also remain the same $\left(a_{p}=0.61\right.$ and $\left.V_{x}=50,000\right)$. The parameters would generate the outer dashed straight line shown in Fig. 17. If we want to generate a straight line cutting more data points, as in the case of Fig. 10, we could maintain the same parameters but make $V_{x}$ equal to 25,000. This generates the dash-dot straight line in Fig. 17. Although this shows that the VSD model encompasses fractal or Pareto distributions, note that none of the straight lines in Fig. 17 are as accurate as the curves generated by the VSD.

\section{Summary and Conclusions}

Indexation and normalization of the natural gas endowment has been demonstrated with the use of a variable shape distribution (VSD) model and data published by the USGS for Canada, the United States, and LAC. The VSD model encompasses fractal or Pareto distributions as well as the deviations from straight lines on log-log coordinates. The normalized modeling results for Canada, the United States, and LAC have been compared with other regions including Europe, Asia Pacific, the Middle East and North Africa, and the FSU using log-log crossplots of cumulative number of provinces versus the normalized sizes of provinces. The comparison shows that the LAC curve has a clearly unique convex shape at the larger normalized endowments, while the complete curve has the shape of an inverted "S". This is different than the other regions considered (with the possible exception of the FSU) that generally show distinctive concave shapes throughout the lengths of the curves.

The unique shape of the LAC curve suggests that the LAC natural gas endowment is probably much larger than estimated in previous studies. The endowment for 29 provinces evaluated by the USGS is 857 TCFG (855 TCFG using the VSD model), while the endowment for 128 provinces recognized by the USGS to exist in LAC countries is estimated at 1,487 TCFG by the VSD model. If the VSD curve is assumed to be concave throughout (as opposed to convex at the largest provinces), the endowment is estimated at 1,077 TCFG for 29 provinces and 1,816 TCFG for 128 provinces. Extended research, exploration and development should help move the LAC curve towards a more concave shape.

\section{Acknowledgements}

Portions of this paper were presented as SPE 139247 at the SPE Latin American and Caribbean Petroleum Engineering Conference, held in Lima, Peru, 1-3 December 2010. Parts of the research were funded by the Centre for Research in Energy and Minerals Economics (CREME) at Curtin University in Australia, the Natural Sciences and Engineering Research Council of 
Canada (NSERC), the Alberta Energy Research Institute (AERI), ConocoPhillips, the Schulich School of Engineering at the University of Calgary and Servipetrol Ltd. Their contributions are gratefully acknowledged.

\section{Appendix A: Nomenclature}

$a_{p}$-absolute value of slope of straight line approximated from USGS data points with larger province volumes (same as slope of Pareto distribution).

$D$ - fractal dimension in Fig. 10

$N_{m}$ - minimum number of USGS provinces (=1).

$N_{t}$ - cumulative number of provinces.

$N_{x}$ - maximum number of provinces.

$r^{2}-$ coefficient of determination in Fig. 10

$S$ - severity exponent that controls the steepness of the slope of the estimated VSD curve where it separates from the Pareto straight line (on the right hand side of the distribution, near the largest volumes).

$V_{i}-$ volumetric size (endowment) of a petroleum province

$V_{m}$ - minimum USGS province volume

$V_{s}$ - approximate volume at which the USGS data begins to deviate from the Pareto straight line (on the right hand side of the distribution, near the largest volumes).

$V_{t f}$ final, estimated volume of a province

$V_{x}$ - maximum volume given by the Pareto straight line (at $N_{m}=1$ ).

$\alpha$ - slope of Pareto straight line in Fig. 10

$\psi$ - separation ratio that controls the amount of separation between the Pareto straight line and the estimated VSD curve (on the right hand side of the distribution, near the largest volumes).

\section{Appendix B: Acronyms}

$\mathrm{BCFG}=$ billion cubic feet of gas

FSU $=$ former Soviet Union

GEM = global energy market 
LAC $=$ Latin America and the Caribbean

MMS = Minerals Management Service

$\mathrm{TCFG}=$ trillion cubic feet of gas

USGS = United States Geological Survey

VSD $=$ variable shape distribution model

\section{References}

Aguilera RF (2006) Assessing the long run availability of global fossil energy resources. PhD Dissertation, Colorado School of Mines, Golden, Colorado, USA

Aguilera RF, Aguilera R (2010) Oil, natural gas, and NGL endowment in North, Central, and South America. SPE Econ Manage 2(2): 92-98

Aguilera RF, Eggert RG, Lagos G, Tilton JE (2009) Depletion and the future availability of petroleum resources. Energy J 30 (1): $161-194$

Barton CC, Scholz CH (1995) The fractal size and spatial distribution of hydrocarbon accumulations. In: Barton CC, LaPointe PR (eds) Fractals in petroleum geology and earth processes. Plenum Press, New York: 13-34

Charpentier RR, Klett TR, Attanasi ED (2007) Database for assessment unit-scale analogs (exclusive of the United States). United States Geological Survey Open-file Report 2007-1404

Crovelli RA, Barton CC (1993) Fractals and the Pareto distribution applied to petroleum accumulation-size distributions. United States Geological Survey Open-File Report 91-18

Drew LJ (1990) Oil and gas forecasting reflections of a petroleum geologist: Oxford University Press, New York. International Association for Mathematical Geology, Studies in Mathematical Geology 2: 252

Drew LJ (1997) Undiscovered petroleum and mineral resources, assessment and controversy. Plenum Press, New York and London

Drew LJ, Root DH, Bawiec WJ (1979) Estimating future rates of petroleum discovery. Paper SPE 7722 presented at the Permian basin hydrocarbon economics and evaluation symposium, Dallas, Texas, USA 
Drew LJ, Attanasi ED, Schuenemeyer JH (1988) Observed oil and gas field size distributions - a consequence of the discovery process and prices of oil and gas. Math Geol 20 (8) 939-953

Klett TR, Ahlbrandt TS, Schmoker JW, Dolton GL (1997) Ranking of the world's oil and gas provinces by known petroleum volumes. United States Geological Survey Open-file Report 97-463

Minerals Management Service (1996) An assessment of the undiscovered hydrocarbon potential of the nation's outer continental shelf. OCS Report MMS 96-0034, US DOI Minerals Management Service, Herndon, Virginia, USA

SPE/WPC/AAPG/SPEE/SEG (2011) Petroleum Resources Management System (PRMS).

USGS National Oil and Gas Resource Assessment Team (1995) National oil and gas assessment (CD-ROM). Denver, Colorado, USA.

USGS World Energy Assessment Team (2000) World petroleum assessment (CD-ROM). Digital Data Series DDS-60, Denver, Colorado, USA 
Table 1 Terms and definitions used throughout this study. USGS (2000) definitions are highlighted by asterisks.

\begin{tabular}{|c|c|}
\hline Cumulative Production* & The reported cumulative volume that has been produced. \\
\hline Endowment Volume* & $\begin{array}{l}\text { The sum of the known volume (cumulative production plus remaining reserves) and } \\
\text { undiscovered volume. }\end{array}$ \\
\hline Future Volume* & $\begin{array}{l}\text { The sum of the remaining reserves and undiscovered volume. Cumulative production does } \\
\text { not contribute to the future volume, neither does reserve growth. }\end{array}$ \\
\hline Known Volume* & The sum of cumulative production and remaining reserves. \\
\hline Petroleum Province* & $\begin{array}{l}\text { An area having characteristic dimensions of perhaps hundreds to thousands of kilometers } \\
\text { encompassing a natural geologic entity (for example, sedimentary basin, thrust belt, delta) or } \\
\text { some combination of contiguous geologic entities. }\end{array}$ \\
\hline Remaining Reserves* & $\begin{array}{l}\text { The volume in discovered fields that has not yet been produced. Remaining reserves are } \\
\text { equal to known volumes minus cumulative production. }\end{array}$ \\
\hline Reserve Growth* & $\begin{array}{l}\text { The increases in 'known' volumes that commonly occur as fields are developed and } \\
\text { produced. It is synonymous with field growth and appreciation. }\end{array}$ \\
\hline Undiscovered Volume* & $\begin{array}{l}\text { The volumes postulated by the USGS, from geologic information and theory, to exist } \\
\text { outside of known volumes. }\end{array}$ \\
\hline Future reserve growth & This accounts for growth in 'future' volumes (Aguilera, 2006). \\
\hline Index & $\begin{array}{l}\text { The volume of conventional natural gas in the province with the largest gas endowment in a } \\
\text { given region. }\end{array}$ \\
\hline Normalized Endowment & $\begin{array}{l}\text { The endowment volume of natural gas in each petroleum province divided by the index in a } \\
\text { given region. }\end{array}$ \\
\hline
\end{tabular}


Table 2 Conventional gas endowment for Canada and the United States (Source: USGS, 1995, 2000; MMS, 1996; Klett et al.,

1997); calculated endowment using the VSD model, indexes and normalized endowments. Index corresponds to the volume in the petroleum province with the maximum endowment and is highlighted with asterisks.

\begin{tabular}{|c|c|c|c|c|c|c|}
\hline (1) & (2) & (3) & (4) & (5) & (6) & (7) \\
\hline & & Cumulative & USGS & USGS-based & VSD Model & VSD-based \\
\hline & & \# of CAN\&US & Gas & Normalized & Calculated & Normalized \\
\hline & & Provinces & Endowment & Gas & Endowment & Gas \\
\hline Province Code & Province Name & $\mathrm{N}_{\mathrm{t}}$ & (BCFG) & Endowment & (BCFG) & Endowment \\
\hline & TOTAL FOR ALL PROVINCES & & $1,687,228$ & & $1,684,214$ & \\
\hline 5047 & Western Gulf & 1 & 319690* & 1.0000 & $323882^{*}$ & 1.0000 \\
\hline 5097 & Gulf of Mexico - Cenozoic Province & 2 & 234,200 & 0.7326 & 198,173 & 0.6119 \\
\hline 5044 & Permian Basin & 3 & 110,470 & 0.3456 & 145,648 & 0.4497 \\
\hline 5058 & Anadarko Basin & 4 & 107,300 & 0.3356 & 115,308 & 0.3560 \\
\hline 5001 & Northern Alaska & 5 & 96,500 & 0.3019 & 95,061 & 0.2935 \\
\hline 5243 & Alberta Basin & 6 & 90,565 & 0.2833 & 80,396 & 0.2482 \\
\hline 5200 & East Greenland Rift Basins & 7 & 80,709 & 0.2525 & 69,200 & 0.2137 \\
\hline 5049 & Louisiana - Mississippi Salt Basins & 8 & 72,290 & 0.2261 & 60,334 & 0.1863 \\
\hline 5078 & Chukchi & 9 & 51,800 & 0.1620 & 53,125 & 0.1640 \\
\hline 5043 & Palo Duro Basin & 10 & 48,400 & 0.1514 & 47,142 & 0.1456 \\
\hline 5081 & Beaufort Shelf & 11 & 43,500 & 0.1361 & 42,097 & 0.1300 \\
\hline 5022 & San Juan Basin & 12 & 39,180 & 0.1226 & 37,790 & 0.1167 \\
\hline 5048 & East Texas Basin & 13 & 34,800 & 0.1089 & 34,072 & 0.1052 \\
\hline 5099 & Atlantic - Mesozoic Province & 14 & 27,500 & 0.0860 & 30,835 & 0.0952 \\
\hline 5031 & Williston Basin & 15 & 22,290 & 0.0697 & 27,997 & 0.0864 \\
\hline 5245 & Rocky Mountain Deformed Belt & 16 & 18,295 & 0.0572 & 25,491 & 0.0787 \\
\hline 5062 & Arkoma Basin & 17 & 18,080 & 0.0566 & 23,266 & 0.0718 \\
\hline 5037 & S.W. Wyoming & 18 & 17,880 & 0.0559 & 21,283 & 0.0657 \\
\hline 5244 & Williston Basin & 19 & 17,756 & 0.0555 & 19,505 & 0.0602 \\
\hline 5215 & Labrador-Newfoundland Shelf & 20 & 15,523 & 0.0486 & 17,907 & 0.0553 \\
\hline 5010 & San Joaquin Basin & 21 & 15,070 & 0.0471 & 16,465 & 0.0508 \\
\hline 5036 & Wyoming Thrust Belt & 22 & 14,680 & 0.0459 & 15,160 & 0.0468 \\
\hline 5045 & Bend Arch - Fort Worth Basin & 23 & 13,850 & 0.0433 & 13,976 & 0.0432 \\
\hline 5009 & Sacramento Basin & 24 & 12,520 & 0.0392 & 12,897 & 0.0398 \\
\hline 5063 & Michigan Basin & 25 & 9,880 & 0.0309 & 11,914 & 0.0368 \\
\hline 5098 & Gulf of Mexico - Mesozoic Province & 26 & 9,700 & 0.0303 & 11,015 & 0.0340 \\
\hline 5003 & Southern Alaska & 27 & 9,640 & 0.0302 & 10,192 & 0.0315 \\
\hline 5020 & Uinta - Piceance Basin & 28 & 9,240 & 0.0289 & 9,437 & 0.0291 \\
\hline 5094 & Los Angeles Basin & 29 & 8,610 & 0.0269 & 8,742 & 0.0270 \\
\hline 5013 & Ventura Basin & 30 & 7,700 & 0.0241 & 8,103 & 0.0250 \\
\hline 5091 & Pacific Northwest & 31 & 7,000 & 0.0219 & 7,514 & 0.0232 \\
\hline 5084 & North Aleutian Basin & 32 & 6,800 & 0.0213 & 6,970 & 0.0215 \\
\hline 5083 & Navarin Basin & 33 & 6,200 & 0.0194 & 6,468 & 0.0200 \\
\hline 5092 & Central California & 34 & 5,200 & 0.0163 & 6,002 & 0.0185 \\
\hline 5089 & Gulf of Alaska & 35 & 4,900 & 0.0153 & 5,572 & 0.0172 \\
\hline 5065 & Black Warrior Basin & 36 & 4,740 & 0.0148 & 5,172 & 0.0160 \\
\hline 5093 & Santa Barbara - Ventura & 37 & 4,600 & 0.0144 & 4,802 & 0.0148 \\
\hline 5039 & Denver Basin & 38 & 4,250 & 0.0133 & 4,457 & 0.0138 \\
\hline 5033 & Powder River Basin & 39 & 4,200 & 0.0131 & 4,137 & 0.0128 \\
\hline 5082 & Hope Basin & 40 & 4,100 & 0.0128 & 3,840 & 0.0119 \\
\hline 5035 & Wind River Basin & 41 & 4,040 & 0.0126 & 3,563 & 0.0110 \\
\hline 5061 & Southern Oklahoma & 42 & 3,720 & 0.0116 & 3,304 & 0.0102 \\
\hline 5055 & Nemaha Uplift & 43 & 3,270 & 0.0102 & 3,064 & 0.0095 \\
\hline 5028 & Central Montana & 44 & 3,140 & 0.0098 & 2,840 & 0.0088 \\
\hline 5085 & St. George Basin & 45 & 3,000 & 0.0094 & 2,631 & 0.0081 \\
\hline
\end{tabular}


Table 2 (Continued) Conventional gas endowment for Canada and the United States (Source: USGS, 1995, 2000; MMS, 1996;

Klett et al., 1997); calculated endowment using the VSD model, indexes and normalized endowments. Index corresponds to the volume in the petroleum province with the maximum endowment and is highlighted with asterisks.

\begin{tabular}{|c|c|c|c|c|c|c|}
\hline (1) & (2) & (3) & (4) & (5) & (6) & (7) \\
\hline & & Cumulative & USGS & USGS-based & VSD Model & VSD-based \\
\hline & & \# of CAN\&US & Gas & Normalized & Calculated & Normalized \\
\hline & & Provinces & Endowment & Gas & Endowment & Gas \\
\hline Province Code & Province Name & $\mathrm{N}_{\mathrm{t}}$ & (BCFG) & Endowment & (BCFG) & Endowment \\
\hline 5021 & Paradox Basin & 46 & 2,920 & 0.0091 & 2,436 & 0.0075 \\
\hline 5067 & Appalachian Basin & 47 & 2,920 & 0.0091 & 2,254 & 0.0070 \\
\hline 5096 & Outer Borderland & 48 & 2,800 & 0.0088 & 2,084 & 0.0064 \\
\hline 5002 & Central Alaska & 49 & 2,760 & 0.0086 & 1,925 & 0.0059 \\
\hline 5086 & Norton Basin & 50 & 2,700 & 0.0084 & 1,777 & 0.0055 \\
\hline 5090 & Shumagin - Kodiak Shelf & 51 & 2,700 & 0.0084 & 1,639 & 0.0051 \\
\hline 5059 & Sedgwick Basin & 52 & 2,520 & 0.0079 & 1,509 & 0.0047 \\
\hline 5034 & Big Horn Basin & 53 & 2,420 & 0.0076 & 1,389 & 0.0043 \\
\hline 5095 & Inner Borderland & 54 & 2,100 & 0.0066 & 1,276 & 0.0039 \\
\hline 5027 & Montana Thrust Belt & 55 & 1,930 & 0.0060 & 1,171 & 0.0036 \\
\hline 5012 & Santa Maria Basin & 56 & 1,620 & 0.0051 & 1,073 & 0.0033 \\
\hline 5088 & Cook Inlet & 57 & 1,600 & 0.0050 & 981 & 0.0030 \\
\hline 5060 & Cherokee Platform & 58 & 1,580 & 0.0049 & 896 & 0.0028 \\
\hline 5007 & Northern Coastal & 59 & 1,190 & 0.0037 & 816 & 0.0025 \\
\hline 5066 & Cincinnati Arch & 60 & 1,020 & 0.0032 & 742 & 0.0023 \\
\hline 5053 & Cambridge Arch - Central Kansas & 61 & 1,010 & 0.0032 & 673 & 0.0021 \\
\hline 5004 & Western Oregon - Wash. & 62 & 790 & 0.0025 & 609 & 0.0019 \\
\hline 5040 & Las Animas Arch & 63 & 630 & 0.0020 & 549 & 0.0017 \\
\hline 5029 & Southwest Montana & 64 & 600 & 0.0019 & 494 & 0.0015 \\
\hline 5064 & Illinois Basin & 65 & 490 & 0.0015 & 442 & 0.0014 \\
\hline 5018 & Western Great Basin & 66 & 430 & 0.0013 & 395 & 0.0012 \\
\hline 5051 & Superior & 67 & 420 & 0.0013 & 351 & 0.0011 \\
\hline 5005 & Eastern Oregon - Wash. & 68 & 390 & 0.0012 & 310 & 0.0010 \\
\hline 5069 & Piedmont & 69 & 390 & 0.0012 & 273 & 0.0008 \\
\hline 5023 & Albuquerque - Santa Fe Rift & 70 & 360 & 0.0011 & 239 & 0.0007 \\
\hline 5019 & Eastern Great Basin & 71 & 330 & 0.0010 & 208 & 0.0006 \\
\hline 5332 & Salton Trough & 72 & 300 & 0.0009 & 179 & 0.0006 \\
\hline 5094 & Los Angeles Basin OCS & 73 & 300 & 0.0009 & 153 & 0.0005 \\
\hline 5011 & Central Coastal & 74 & 250 & 0.0008 & 130 & 0.0004 \\
\hline 5025 & S. Ariz - S.W. New Mexico & 75 & 200 & 0.0006 & 109 & 0.0003 \\
\hline 5087 & St. Matthew - Hall Basin & 76 & 200 & 0.0006 & 90 & 0.0003 \\
\hline 5024 & Northern Arizona & 77 & 170 & 0.0005 & 73 & 0.0002 \\
\hline 5046 & Marathon Thrust Belt & 78 & 140 & 0.0004 & 59 & 0.0002 \\
\hline 5056 & Forest City Basin & 79 & 70 & 0.0002 & 46 & 0.0001 \\
\hline 5008 & Sonoma - Livermore Basin & 80 & 60 & 0.0002 & 35 & 0.0001 \\
\hline 5041 & Raton Basin - Sierra Grande Uplift & 81 & 40 & 0.0001 & 27 & 0.0001 \\
\hline 5050 & Florida Peninsula & 82 & 40 & 0.0001 & 20 & 0.0001 \\
\hline 5068 & Blue Ridge Thrust Belt & 83 & 30 & 0.0001 & 15 & 0.0000 \\
\hline 5038 & Park Basins & 84 & 20 & 0.0001 & 11 & 0.0000 \\
\hline 5017 & Idaho - Snake River Downwarp & 85 & 10 & 0.0000 & 10 & 0.0000 \\
\hline 5006 & Klamath - Sierra Nevada & 86 & 0 & & & \\
\hline 5015 & San Diego - Ocean Side & 87 & 0 & & & \\
\hline 5026 & South - Central New Mexico & 88 & 0 & & & \\
\hline 5032 & Sioux Arch & 89 & 0 & & & \\
\hline 5042 & Pedernal Uplift & 90 & 0 & & & \\
\hline 5052 & lowa Shelf & 91 & 0 & & & \\
\hline 5057 & Ozark Uplift & 92 & 0 & & & \\
\hline 5054 & Salina Basin & 93 & $<100$ & & & \\
\hline
\end{tabular}


Table 3 USGS (2000) conventional gas endowment for LAC countries; calculated endowment using the VSD model, indexes and normalized endowments. Index corresponds to the volume in the petroleum province with the maximum endowment and is highlighted with asterisks.

\begin{tabular}{|c|c|c|c|c|c|c|}
\hline (1) & (2) & (3) & (4) & (5) & (6) & (7) \\
\hline & & Cumulative & USGS & USGS-based & VSD Model & VSD-based \\
\hline & & \# of LAC & Gas & Normalized & Calculated & Normalized \\
\hline & & Provinces & Endowment & Gas & Endowment & Gas \\
\hline Province Code & Province Name & $\mathrm{N}_{\mathrm{t}}$ & (BCFG) & Endowment & (BCFG) & Endowment \\
\hline & TOTAL FOR ALL PROVINCES & & 857,099 & & 854,959 & \\
\hline 6098 & East Venezuela Basin & 1 & $221679^{\star}$ & 1.0000 & $222,040^{*}$ & 1.0000 \\
\hline 6036 & Santos Basin & 2 & 81,672 & 0.3684 & 81,502 & 0.3671 \\
\hline 5305 & Villahermosa Uplift & 3 & 56,915 & 0.2567 & 59,066 & 0.2660 \\
\hline 6045 & Santa Cruz-Tarija Basin & 4 & 48,092 & 0.2169 & 50,709 & 0.2284 \\
\hline 6099 & Maracaibo Basin & 5 & 44,277 & 0.1997 & 46,031 & 0.2073 \\
\hline 6103 & Tobago Trough & 6 & 42,703 & 0.1926 & 42,700 & 0.1923 \\
\hline 6021 & Guyana Basin & 7 & 42,058 & 0.1897 & 39,937 & 0.1799 \\
\hline 6059 & Magallenes Basin & 8 & 38,848 & 0.1752 & 37,419 & 0.1685 \\
\hline 6034 & Espirito Santo Basin & 9 & 34,509 & 0.1557 & 34,992 & 0.1576 \\
\hline 6055 & Neuquen Basin & 10 & 33,119 & 0.1494 & 32,577 & 0.1467 \\
\hline 6022 & Foz de Amazonas Basin & 11 & 29,840 & 0.1346 & 30,137 & 0.1357 \\
\hline 6035 & Campos Basin & 12 & 25,935 & 0.1170 & 27,661 & 0.1246 \\
\hline 6037 & Pelotas Basin & 13 & 22,806 & 0.1029 & 25,151 & 0.1133 \\
\hline 5304 & Saline-Comalcalco Basin & 14 & 18,669 & 0.0842 & 22,626 & 0.1019 \\
\hline 6060 & North Malvinas Basin & 15 & 16,581 & 0.0748 & 20,110 & 0.0906 \\
\hline 6096 & Llanos Basin & 16 & 15,651 & 0.0706 & 17,636 & 0.0794 \\
\hline 6107 & Lesser Antilles Deformed Belt & 17 & 11,979 & 0.0540 & 15,238 & 0.0686 \\
\hline 6063 & Malvinas Basin & 18 & 11,402 & 0.0514 & 12,953 & 0.0583 \\
\hline 6029 & Sergipe-Alagoas Basin & 19 & 9,741 & 0.0439 & 10,813 & 0.0487 \\
\hline 5301 & Tampico-Misantla Basin & 20 & 8,712 & 0.0393 & 8,849 & 0.0399 \\
\hline 6090 & Middle Magdelena & 21 & 8,294 & 0.0374 & 7,082 & 0.0319 \\
\hline 6081 & Talara Basin & 22 & 7,687 & 0.0347 & 5,530 & 0.0249 \\
\hline 6058 & San Jorge Basin & 23 & 7,339 & 0.0331 & 4,200 & 0.0189 \\
\hline 5302 & Veracruz Basin & 24 & 6,437 & 0.0290 & 3,095 & 0.0139 \\
\hline 5307 & Campeche-Sigsbe Salt Basin & 25 & 5,565 & 0.0251 & 2,210 & 0.0100 \\
\hline 6041 & Putamayo-Orient-Maranon Basin & 26 & 3,212 & 0.0145 & 1,536 & 0.0069 \\
\hline 5308 & Yucatan Platform & 27 & 1,496 & 0.0067 & 1,062 & 0.0048 \\
\hline 6083 & Progreso Basin & 28 & 1,193 & 0.0054 & 776 & 0.0035 \\
\hline 6117 & Greater Antilles Deformed Belt & 29 & 688 & 0.0031 & 672 & 0.0030 \\
\hline 5310 & Sierra Madre de Chiapas-Peten Foldbelt & & NA & & & \\
\hline
\end{tabular}


Table 4 Parameters, variables, and indexes used in VSD analysis and normalizing of regions A through F.

\begin{tabular}{|c|c|c|c|c|c|c|c|c|c|c|c|c|c|c|}
\hline & (1) & (2) & (3) & (4) & (5) & (6) & (7) & (8) & (9) & (10) & (11) & \multicolumn{3}{|c|}{ (12) } \\
\hline & & Index & Index & ap & $\mathrm{Vx}$ & $\psi$ & Vs & $\mathrm{s}$ & $\mathrm{Vm}$ & $\mathrm{Nx}$ & $\mathrm{Nx}$ & \multicolumn{3}{|c|}{ Endowment } \\
\hline & & USGS & VSD & & & & & & & Assessed & Assessed + & Assessed & Assessed & Assessed + \\
\hline & & (TCFG) & (TCFG) & & & & & & & & Unassessed & USGS & VSD & Unassessed \\
\hline & & & & & & & & & & & & (TCFG) & (TCFG) & VSD (TCFG) \\
\hline & Region & & & & & & & & & & & & & \\
\hline A & LAC & 221.679 & 222.040 & 0.547 & 22,691 & 0.01030 & 4,763 & 0.94 & 0.688 & 29 & 128 & 857 & 855 & 1,548 \\
\hline & LAC (concave assumption) & 221.679 & 222.040 & 0.550 & 30,365 & 0.00138 & 363,972 & 0.67 & 0.672 & 29 & 128 & 857 & 1,077 & 1,816 \\
\hline B & Canada and USA & 319.690 & 323.880 & 0.555 & 11,400 & 0.00067 & $4,151,548$ & 0.64 & 0.010 & 85 & 172 & 1,687 & 1,684 & 1,921 \\
\hline C & Former Soviet Union & 1912.983 & 2001.561 & 0.970 & 880 & 3.28000 & 94 & 1643 & 0.100 & 30 & 141 & 3,687 & 3,688 & 5,009 \\
\hline D & Asia Pacific & 120.956 & 120.921 & 0.654 & 1,316 & 0.02300 & 3,669 & 1.23 & 0.100 & 66 & 261 & 888 & 887 & 1,142 \\
\hline E & Europe & 197.584 & 198.289 & 0.796 & 840 & 0.26000 & 83 & 48 & 0.152 & 13 & 62 & 796 & 796 & 1,403 \\
\hline $\mathrm{F}$ & Middle East and North Africa & 611.451 & 596.700 & 0.420 & 38,800 & 0.00150 & 338,515 & 1.05 & 0.005 & 33 & 88 & 3,279 & 3,276 & 3,948 \\
\hline
\end{tabular}




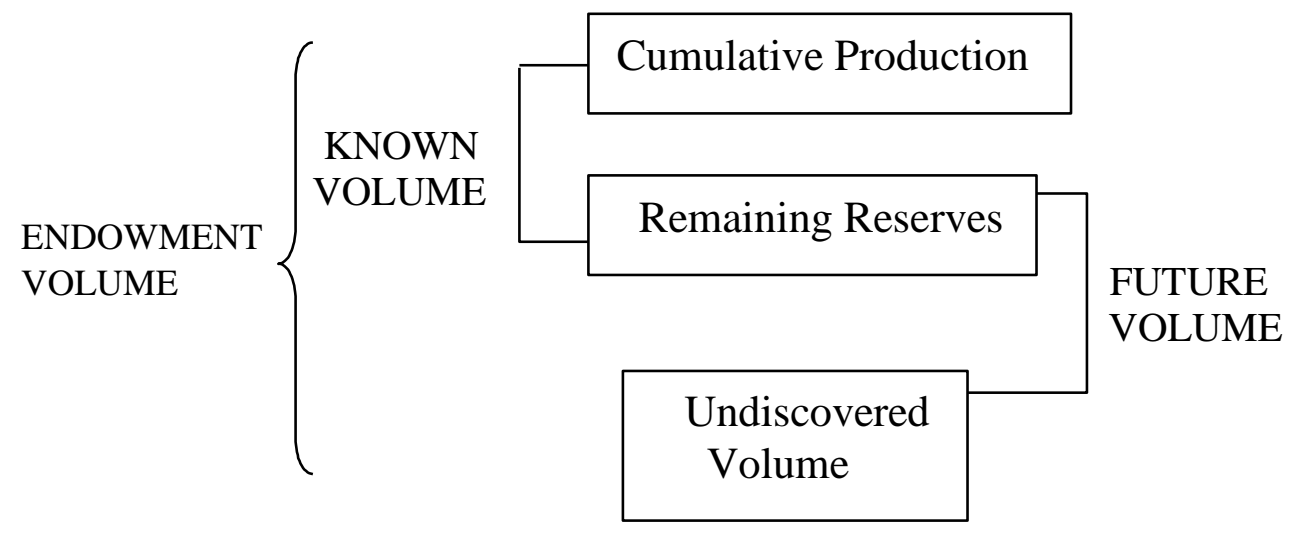

Fig. 1 The relationship between cumulative production, remaining reserves and undiscovered volumes, terminology from USGS, 2000 (Source: Aguilera, 2006). 


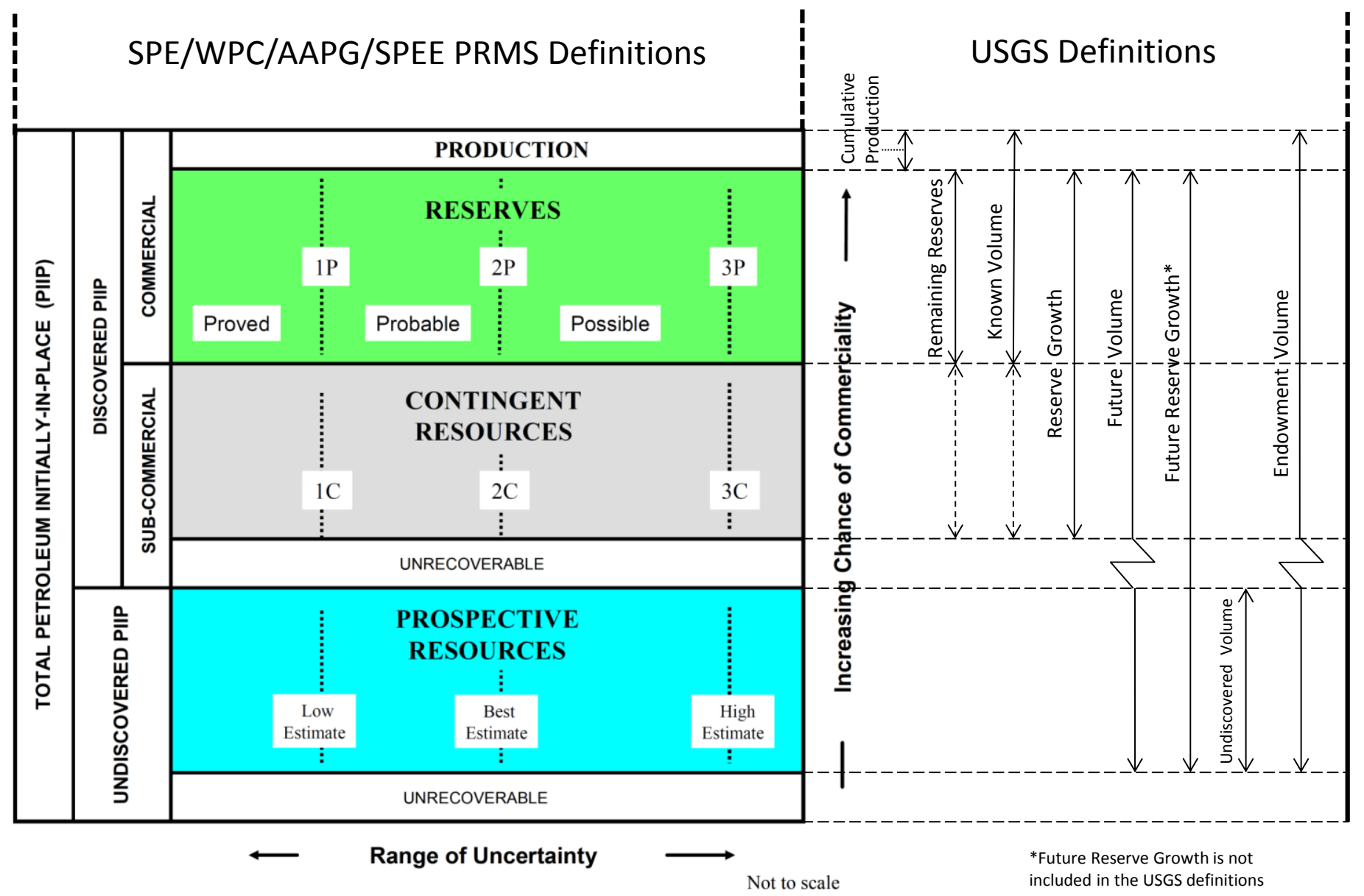

Fig. 2 Comparison between terminology from USGS (2000) and PRMS (2011). 


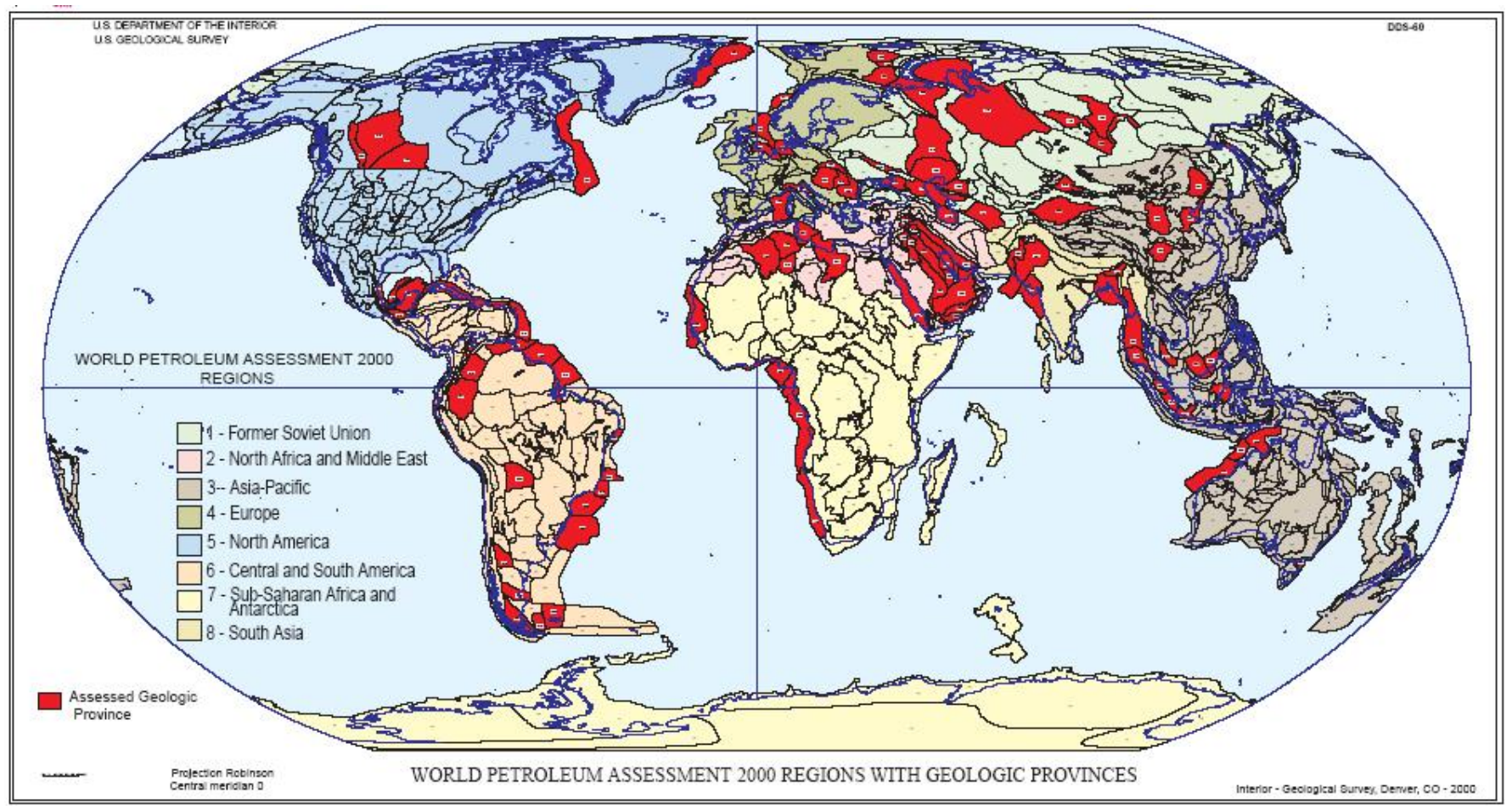

Fig. 3 USGS World Petroleum Assessment regions with geologic provinces (USGS, 2000). In the USGS report, Mexico's endowment is included in the North America region. In this paper, Mexico is included within the LAC assessment. The LAC results are then compared with normalized endowment from other regions around the world. 


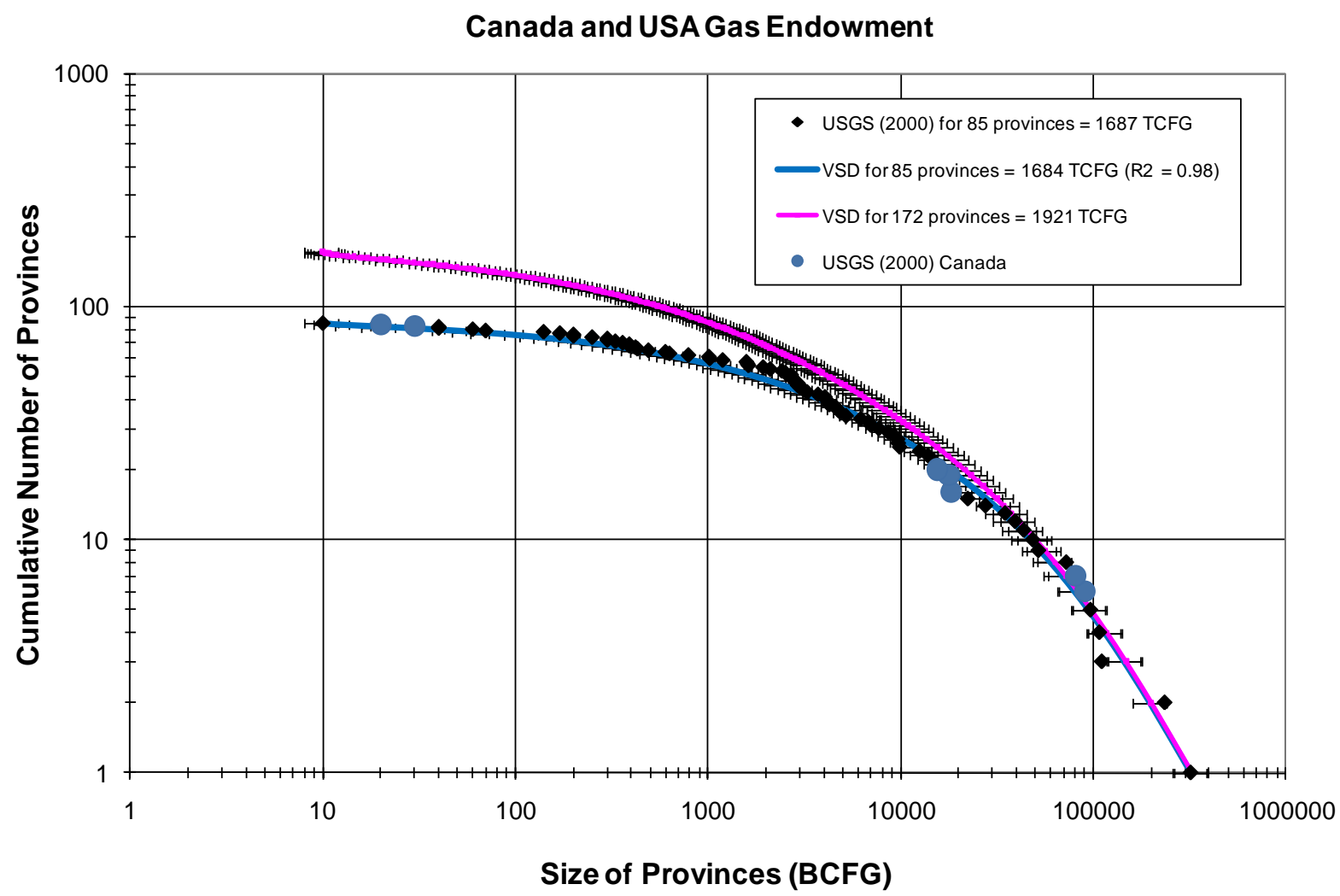

Fig. 4 Conventional natural gas endowment for Canada and the United States. The black diamonds represent endowments published by the USGS (1995, 2000); MMS, 1996; Klett et al. (1997). The solid blue continuous line corresponds to the endowments calculated with the VSD model. The magenta squares show VSD predictions of the endowment for all 172 petroleum provinces recognized by the USGS to exist in Canada and the United States. Horizontal error bars (plus and minus 20\%). 


\section{LAC Gas Endowment}

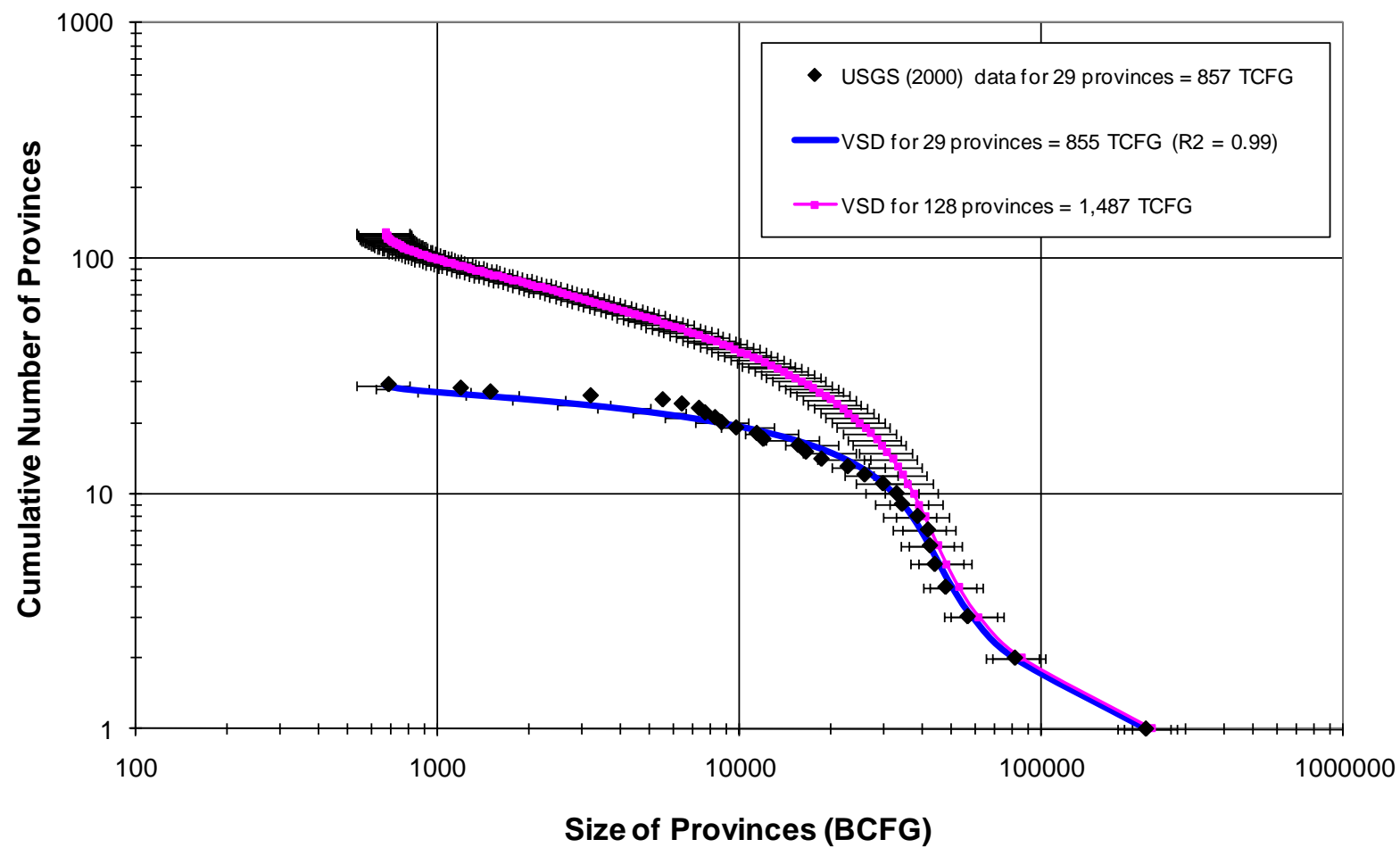

Fig. 5 Conventional natural gas endowment for LAC. The black diamonds represent endowments published by the USGS (2000). The solid blue continuous line corresponds to the endowments calculated with the VSD model. The magenta squares show VSD predictions of the endowment for all 128 petroleum provinces recognized by the USGS to exist in LAC countries. Horizontal error bars (plus and minus 20\%). 


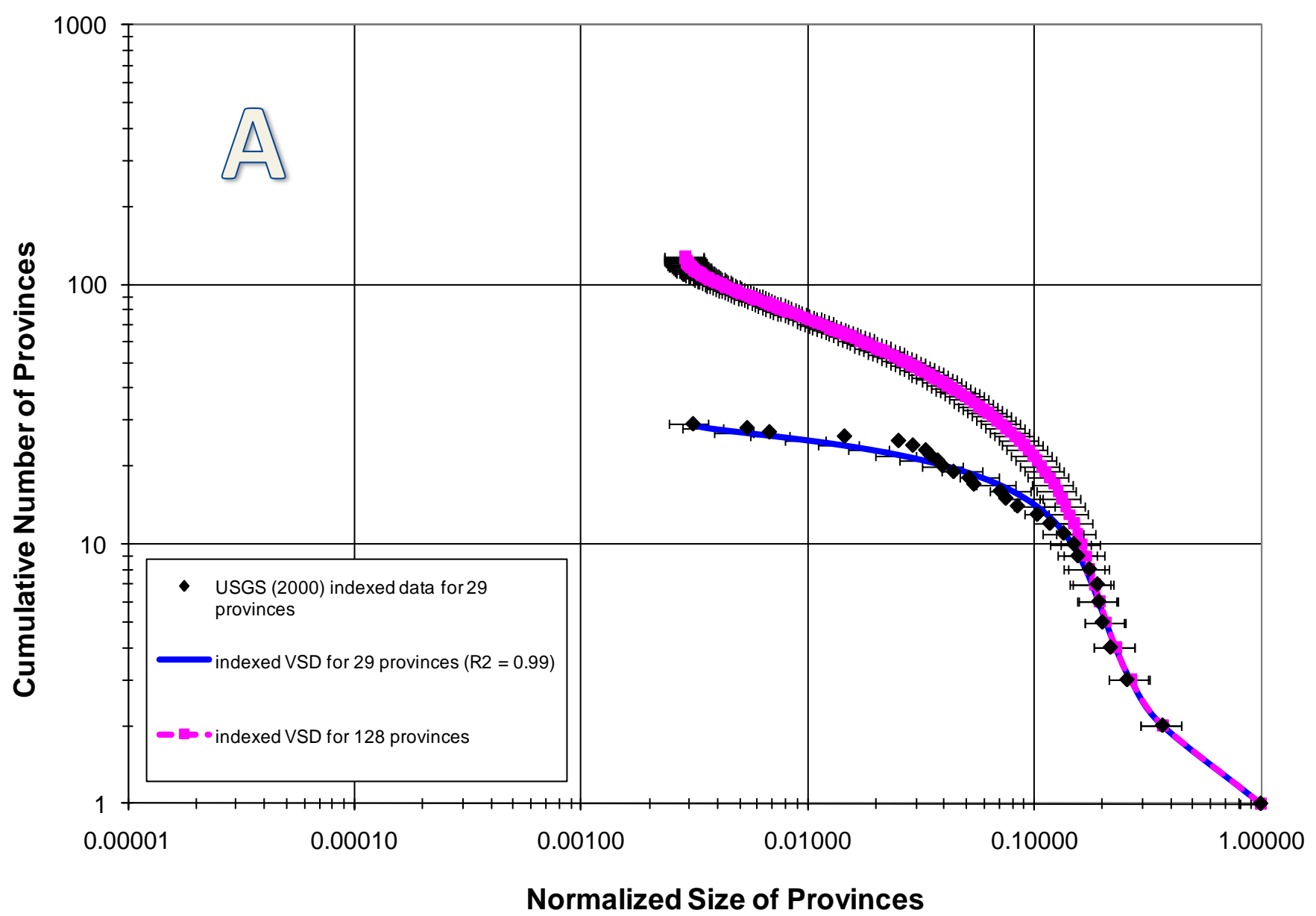

Fig. 6(A) Normalized conventional gas endowment (size of provinces) vs. cumulative number of provinces for LAC countries.

The shape of the curve is convex at large values of the normalized endowments. The shapes of the curves in Figs. 6(B) to 6(G) are generally concave. Horizontal error bars (plus and minus 20\%). 


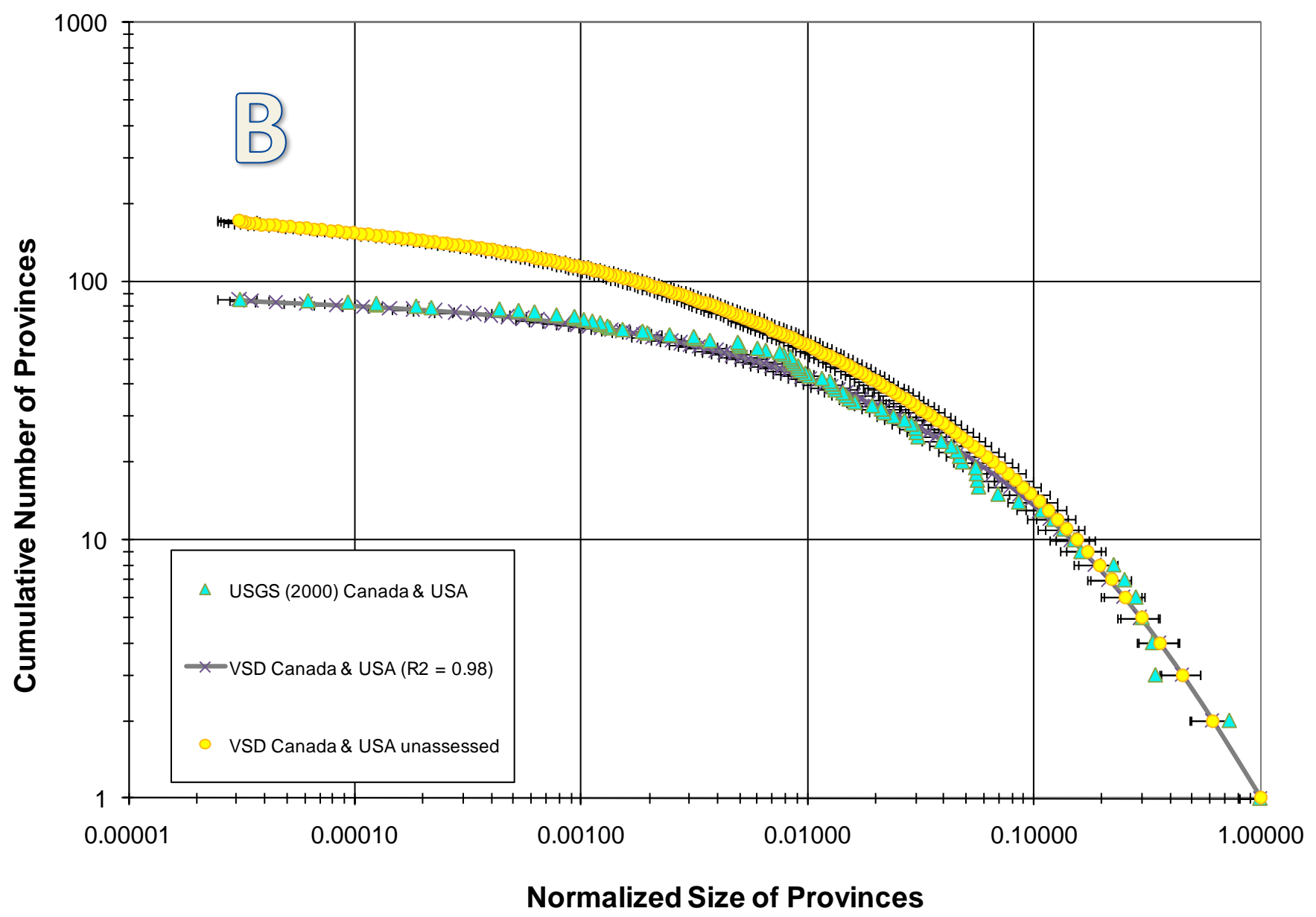

Fig. 6(B) Normalized conventional gas endowment (size of provinces) vs. cumulative number of provinces for the United States and Canada. Horizontal error bars (plus and minus 20\%). 


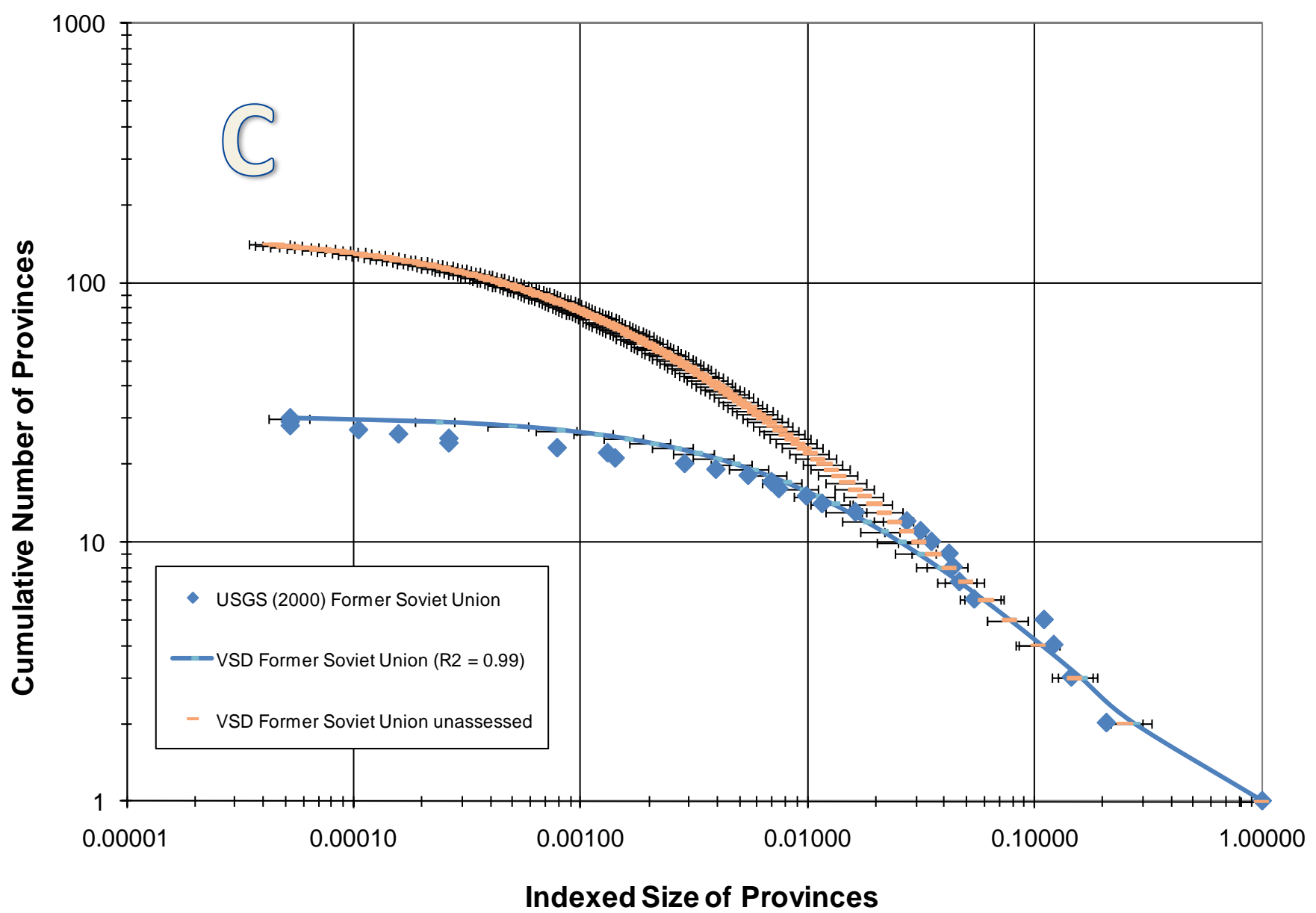

Fig. 6(C) Normalized conventional gas endowment (size of provinces) vs. cumulative number of provinces for the Former Soviet Union. Horizontal error bars (plus and minus 20\%). 


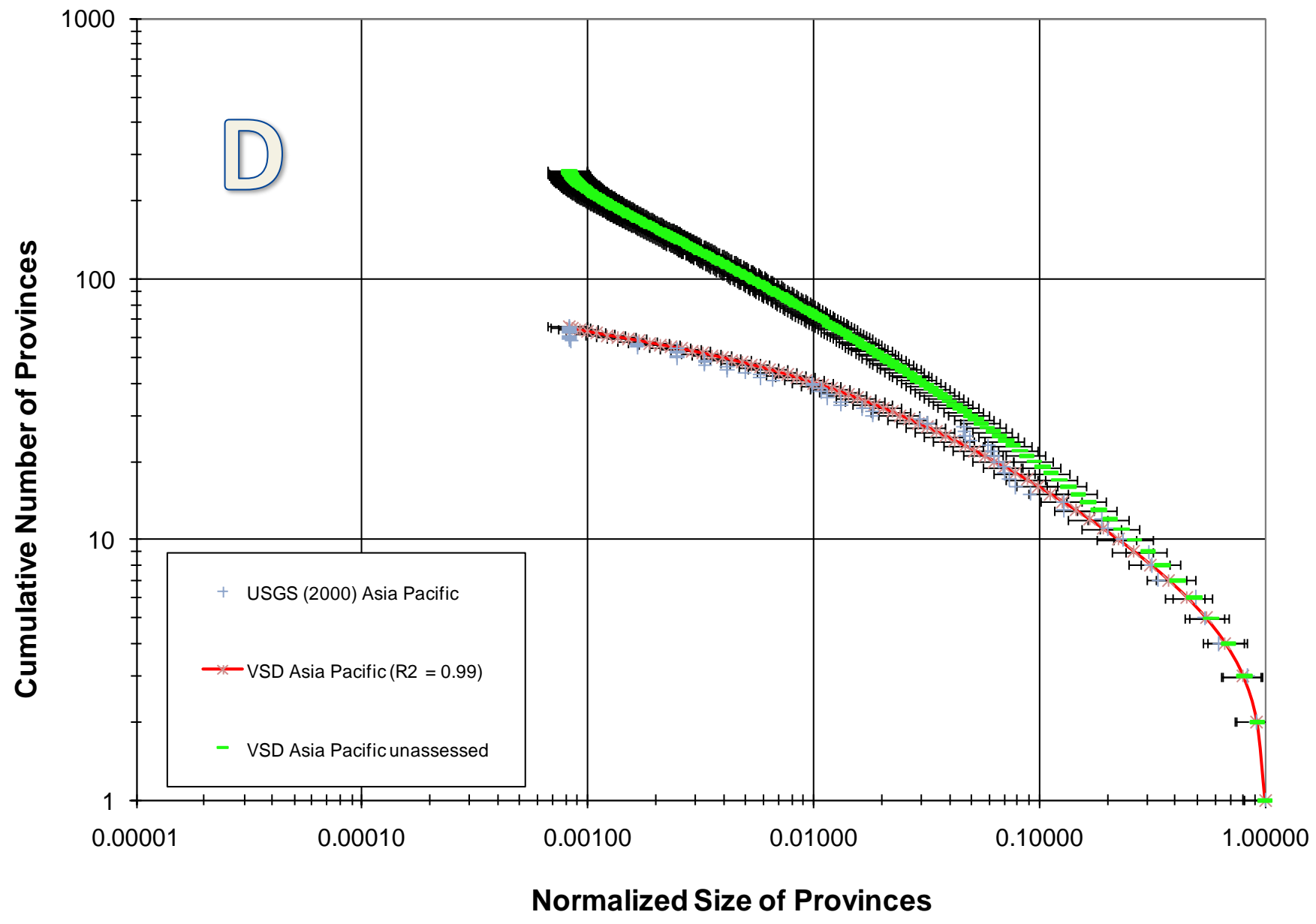

Fig. 6(D) Normalized conventional gas endowment (size of provinces) vs. cumulative number of provinces for Asia Pacific.

Horizontal error bars (plus and minus 20\%). 


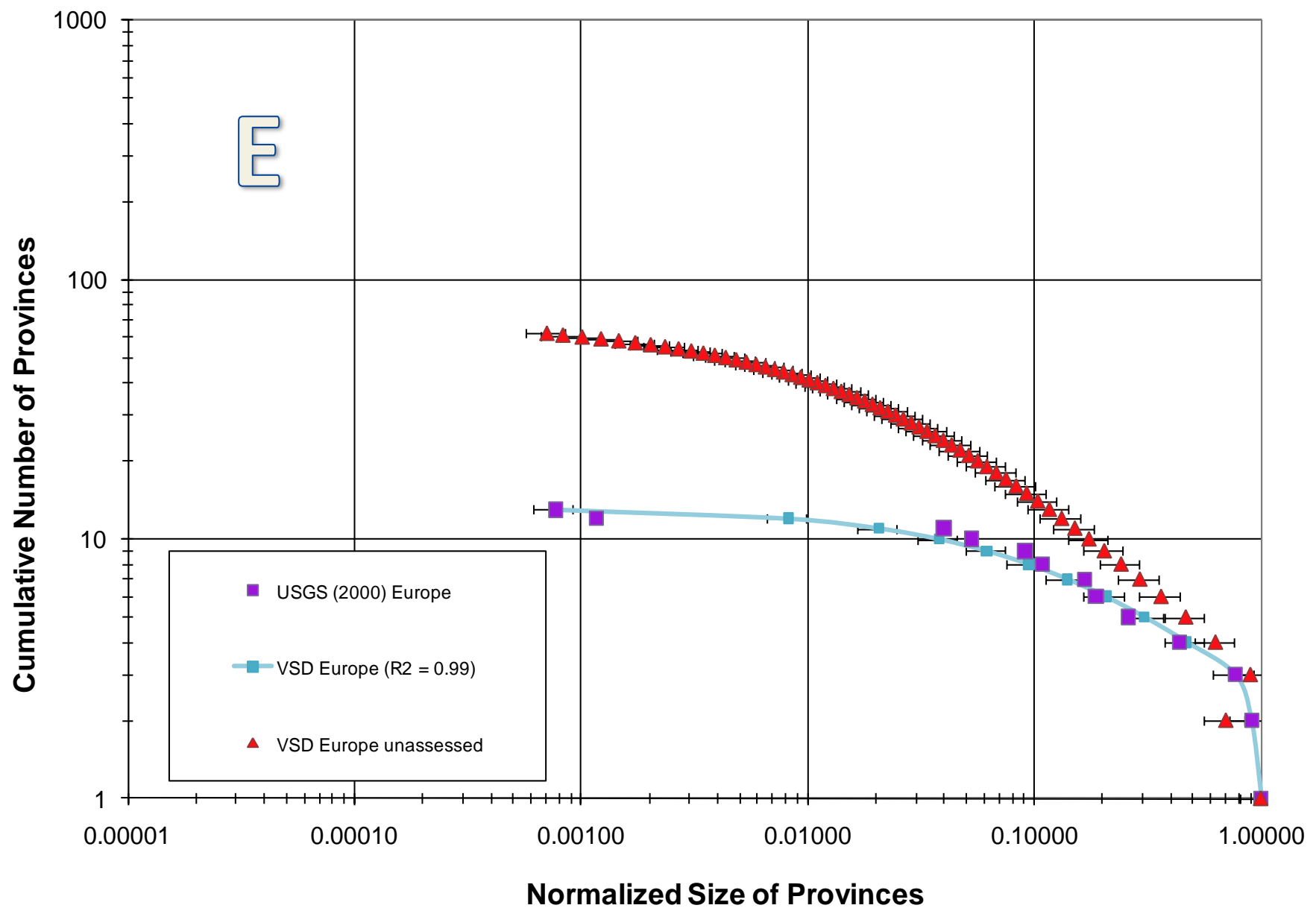

Fig. 6(E) Normalized conventional gas endowment (size of provinces) vs. cumulative number of provinces for Europe. Horizontal error bars (plus and minus 20\%). 


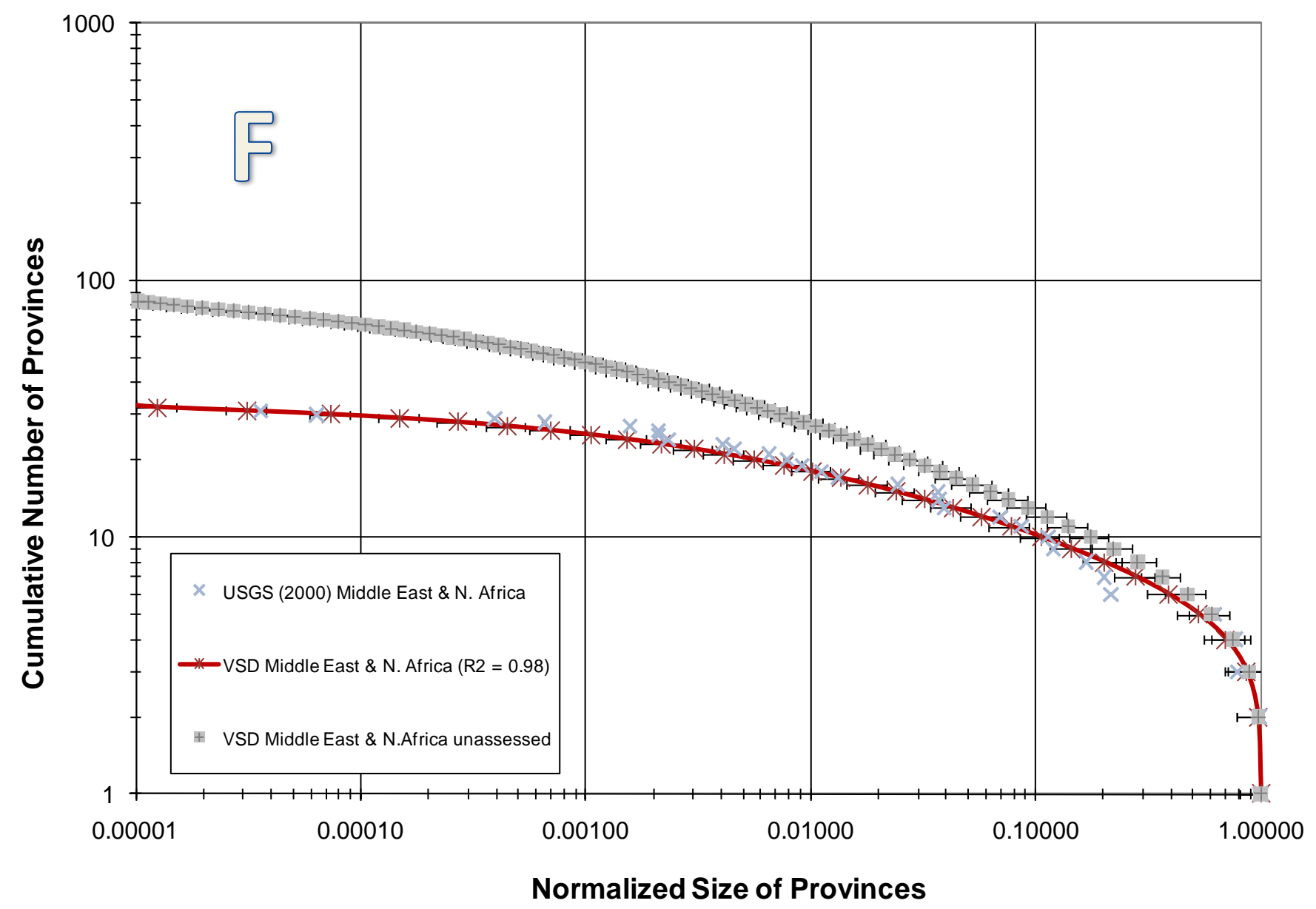

Fig. 6(F) Normalized conventional gas endowment (size of provinces) vs. cumulative number of provinces for Middle East and North Africa. Horizontal error bars (plus and minus 20\%). 


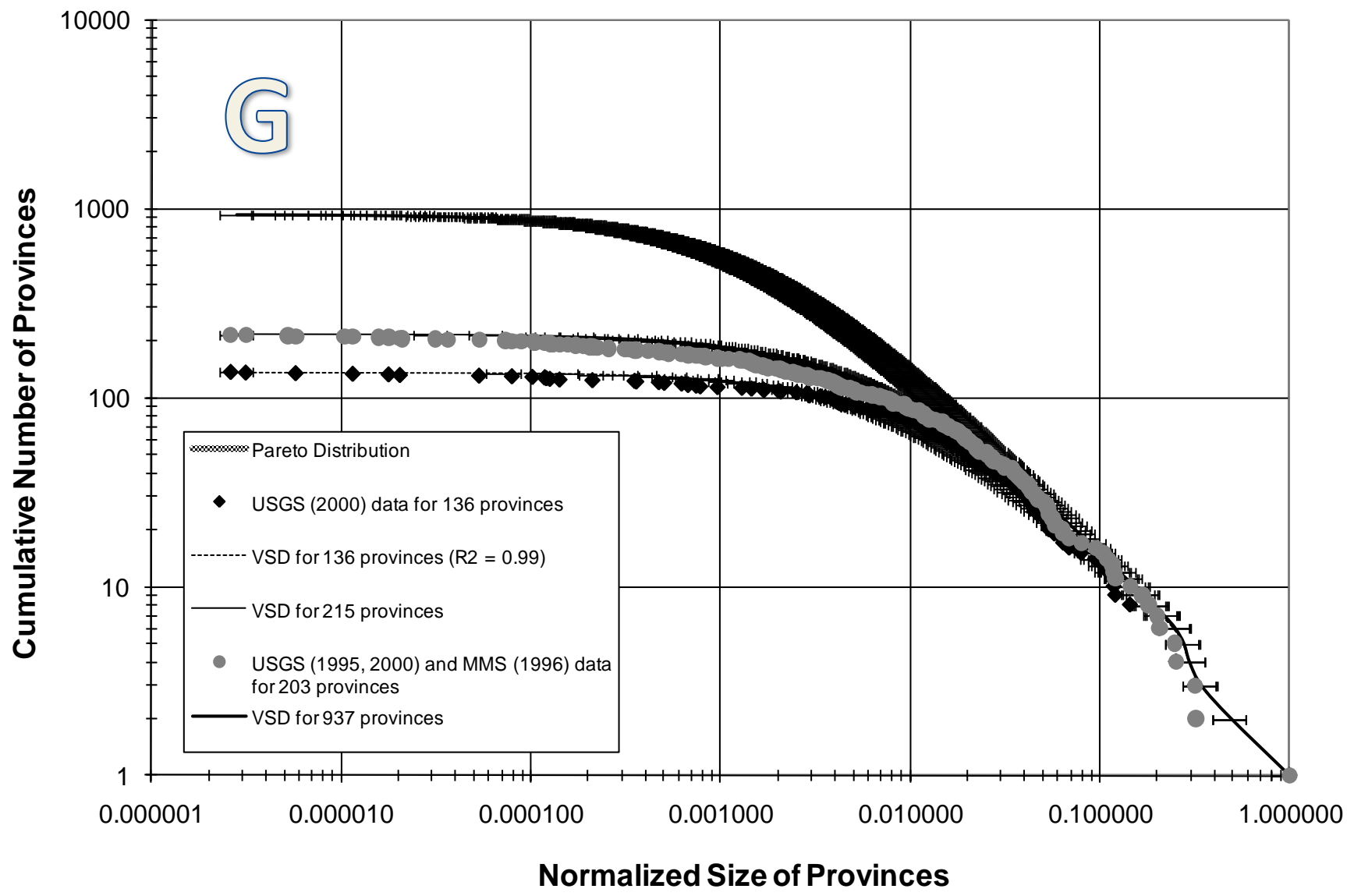

Fig. 6(G) Normalized conventional gas endowment (size of provinces) vs. cumulative number of provinces for the entire world, The shapes of the curves in Figs. 6(B) to 6(G) are generally concave. The shape of the curve in Fig. 6(A) for LAC countries is convex at large values of the normalized endowments. Horizontal error bars (plus and minus 20\%). 


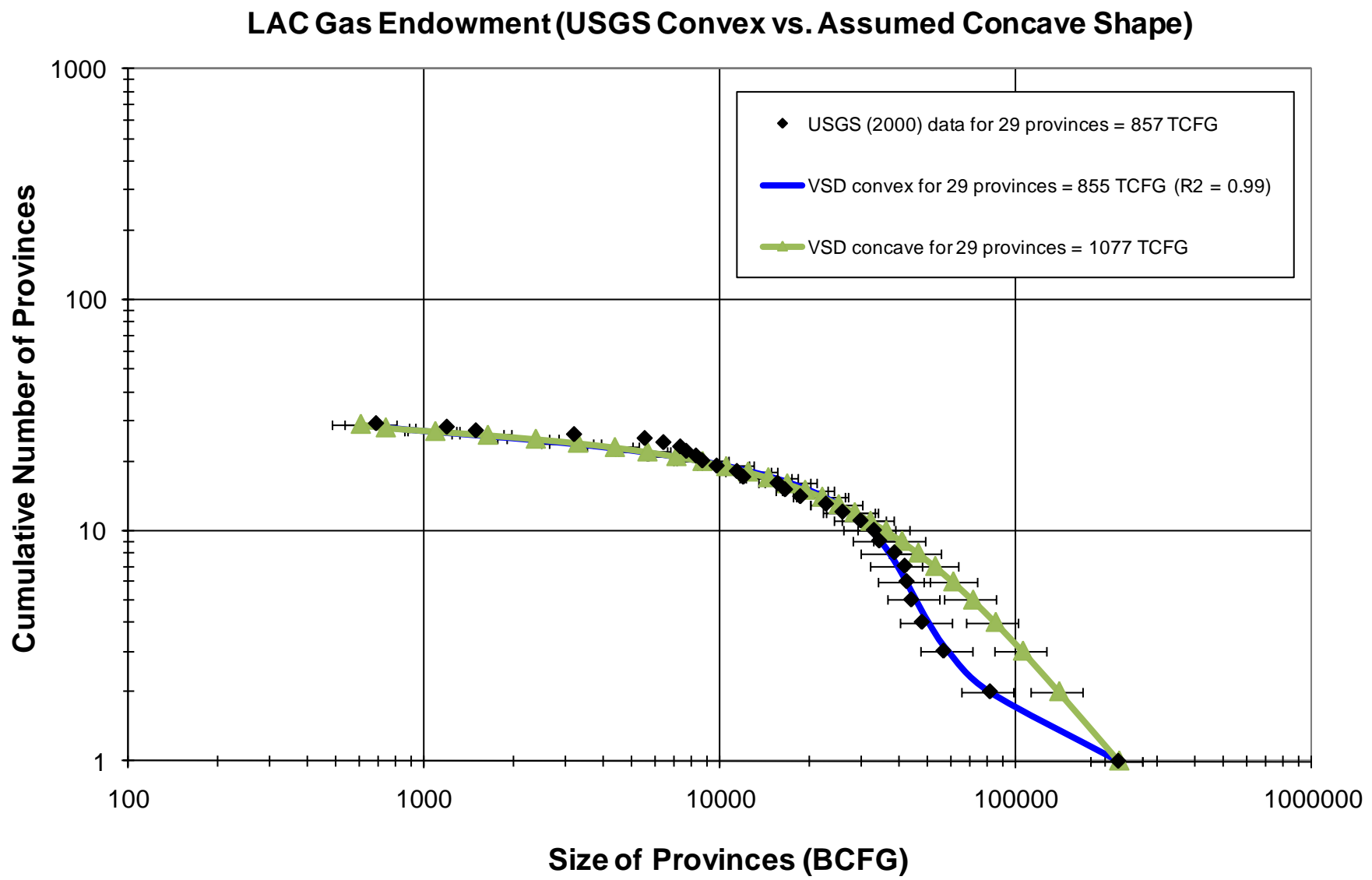

Fig. 7 Conventional natural gas endowment for LAC. The triangles show the additional gas endowment assuming a concave VSD curve for 29 provinces. The assumption of a concave shape like in other petroleum provinces of the world increases the endowment from 855 to 1,077 TCFG. Horizontal error bars (plus and minus 20\%). 


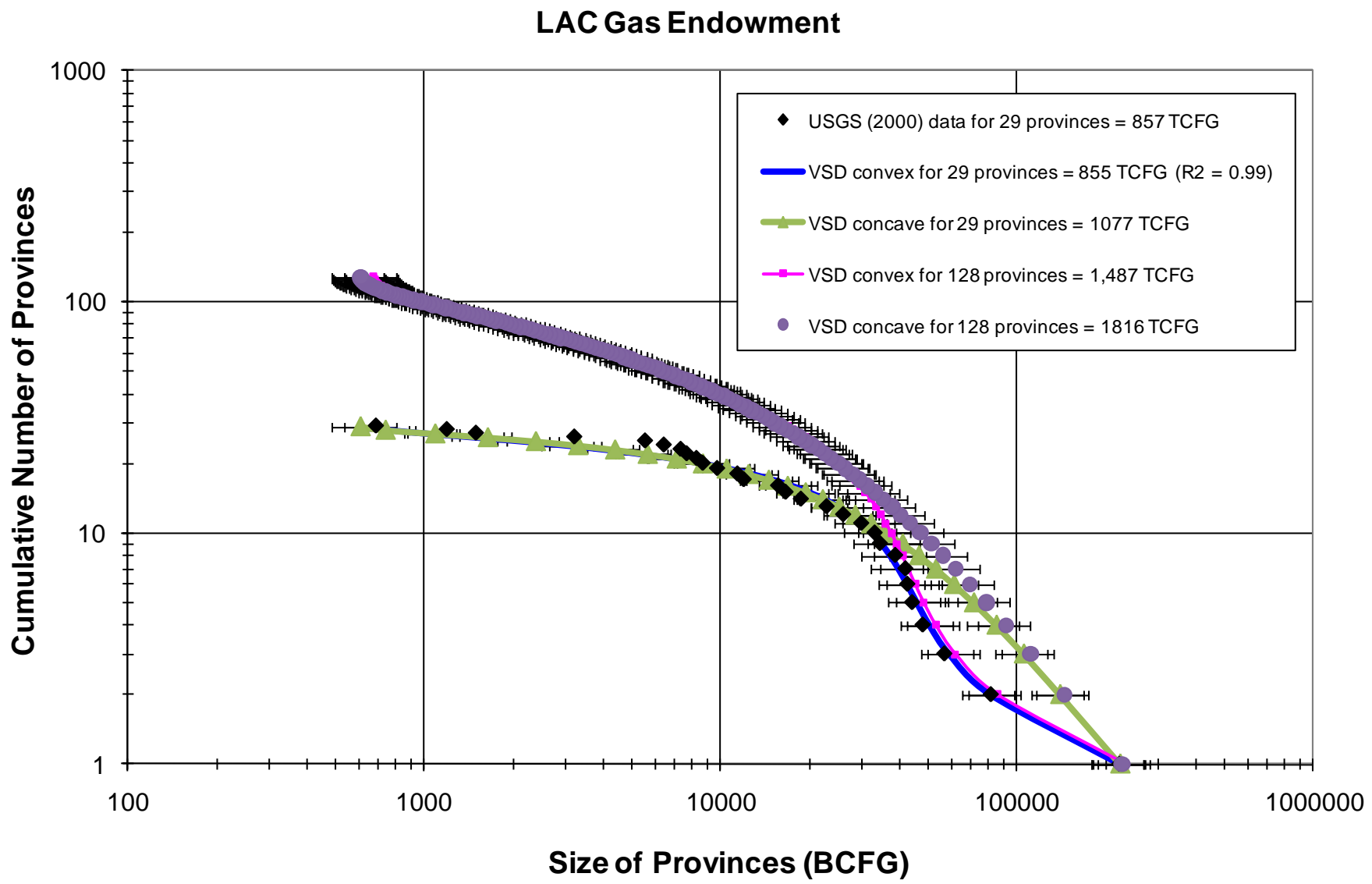

Fig. 8 Conventional natural gas endowment LAC. The circles show the additional gas endowment assuming a concave VSD curve for 128 provinces. The concave assumption increases the endowment from 1,487 to 1,816 TCFG. Horizontal error bars (plus and minus 20\%). 


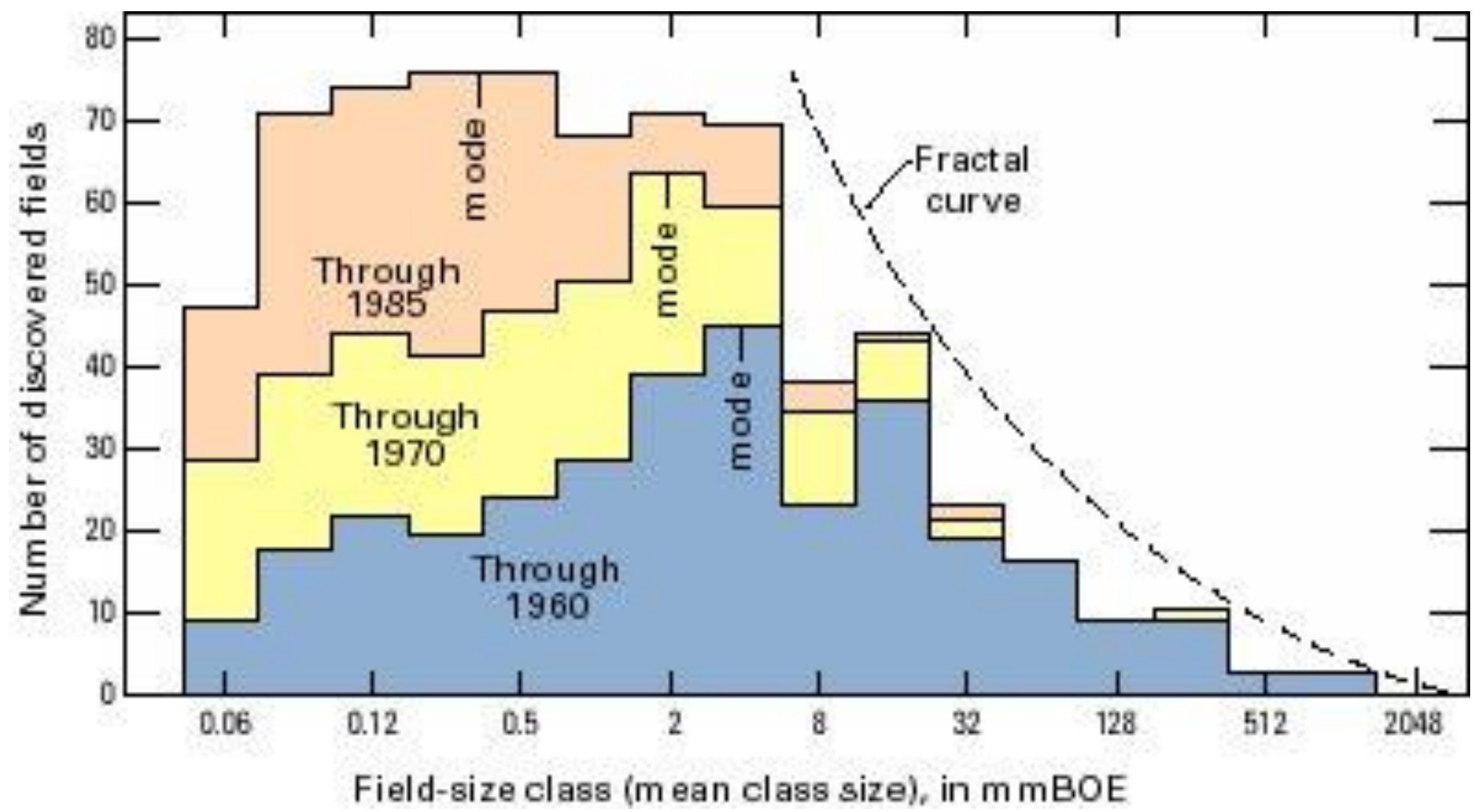

Fig. 9 Observed field size distribution for the Frio Strandplain play, onshore Texas. The distribution has three segments representing the cumulative number of fields discovered through the specified year (Source: Drew, 1990, 1997; Crovelli and Barton, 1993; Barton and Scholz, 1995). 


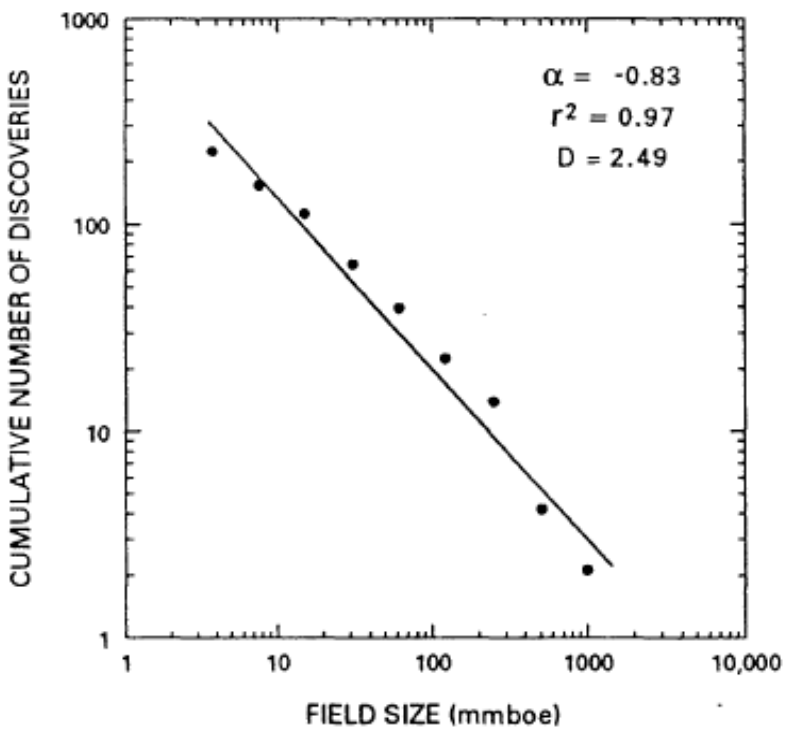

Fig. 10 Cumulative frequency plot of petroleum field sizes for the Frio Strandplain play, onshore Texas. Data points for only the largest 9 fields are shown. The remaining fields have been truncated due to economic considerations (Source: Crovelli and Barton, 1993). 


\section{OBSERVED FIELD DISTRIBUTION, OIL AND GAS, FRIO STRANDPLAIN EXPLORATION PLAY, TEXAS (Source of data: Barton and scholz, 1995)}

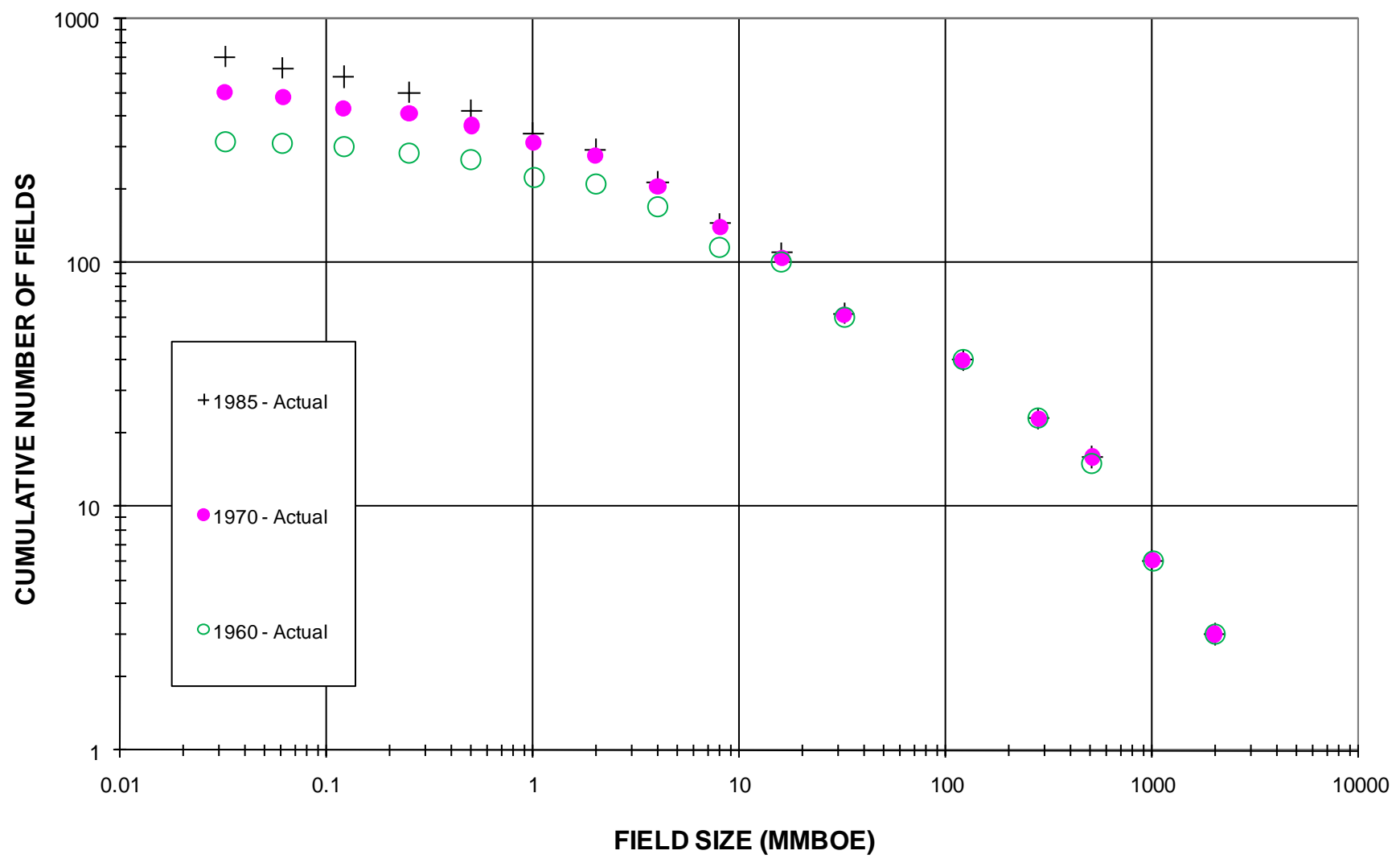

Fig. 11 Log-log plot by time segments of cumulative frequency of oil and gas fields vs. field size (Source: Barton and Scholz, 1995). 
OBSERVED FIELD DISTRIBUTION, OIL AND GAS, FRIO STRANDPLAIN EXPLORATION PLAY,

TEXAS

Actual and Calculated with Variable Shape Distribution (VSD) Model

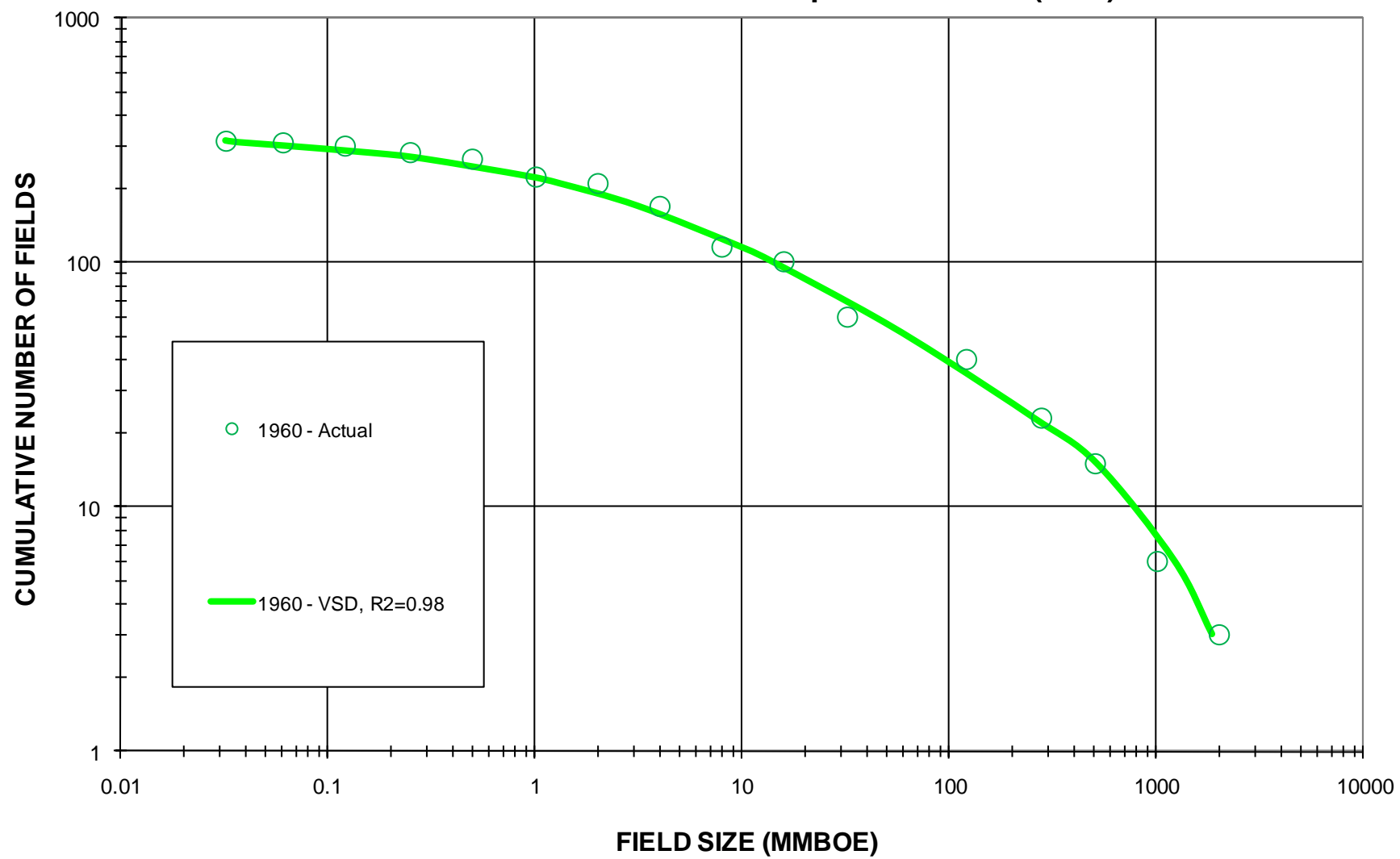

Fig. 12 Log-log plot by time segments of cumulative frequency of oil and gas fields vs. field size to 1960 and best fit obtained with the VSD model. The hydrocarbon endowment is not truncated and is shown even for small fields that were not economic at that point in time. The VSD fits the USGS data with a coefficient of determination $\left(\mathrm{R}^{2}\right)$ equal to 0.98 (Source of actual data: Barton and Scholz, 1995). 


\section{OBSERVED FIELD DISTRIBUTION, OIL AND GAS, FRIO STRAIN EXPLORATION PLAY, TEXAS Actual and Calculated to 1960, and Predicted to 1970 with VSD Model}

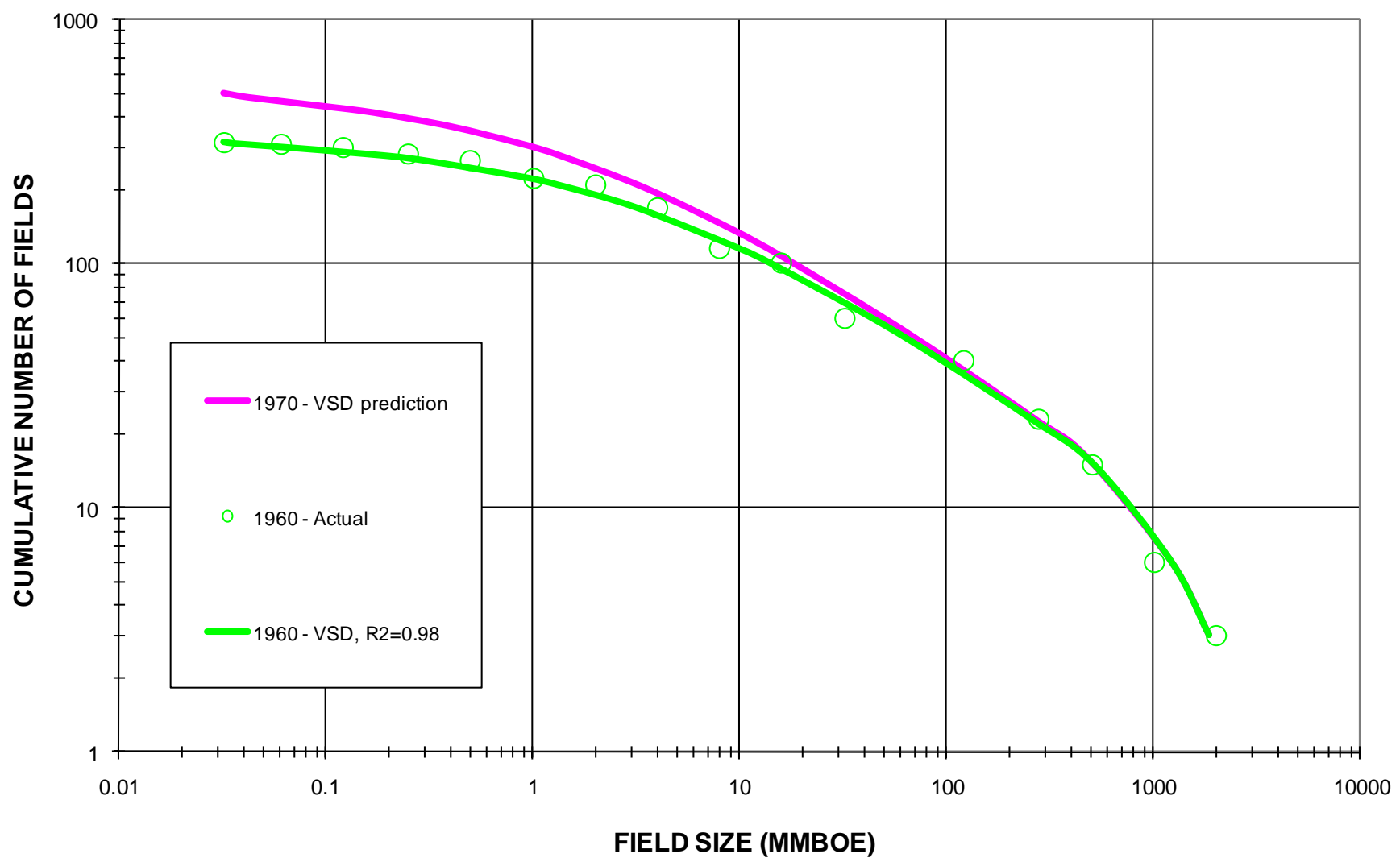

Fig. 13 Log-log plot by time segments of cumulative frequency of oil and gas fields vs. field size and best fit obtained with the VSD model to 1960 (Source of actual data: Barton and Scholz, 1995). Also shown is the predicted distribution of the VSD to 1970. 


\section{OBSERVED FIELD DISTRIBUTION, OIL AND GAS, FRIO STRAIN EXPLORATION PLAY, TEXAS Actual and Calculated to 1960 and 1970 with VSD Model}

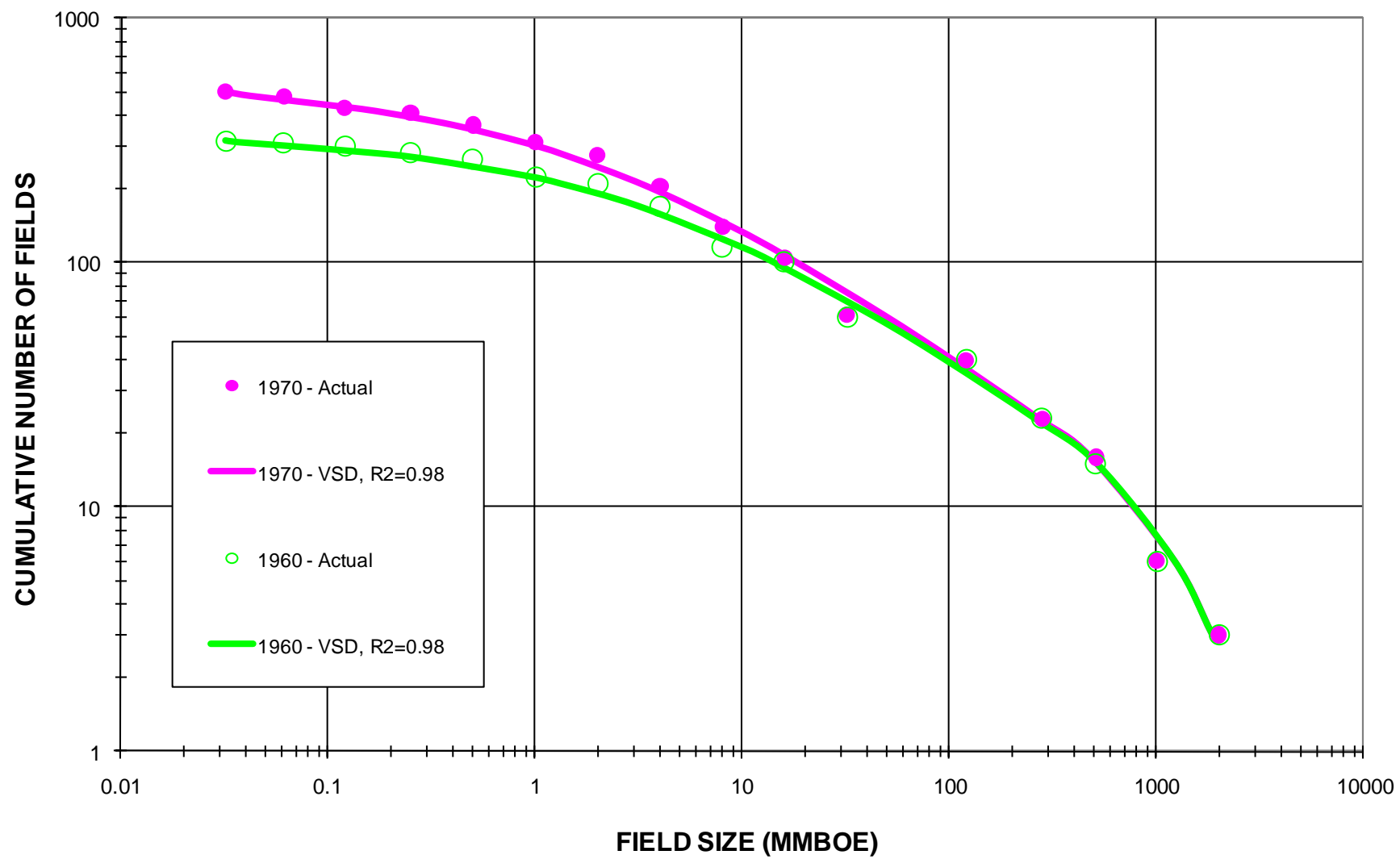

Fig. 14 Log-log plot by time segments of cumulative frequency of oil and gas fields vs. field size and best fits obtained with the VSD model for 1960 and 1970 . The VSD fits the USGS data with coefficients of determination $\left(\mathrm{R}^{2}\right.$ ) equal to 0.98 (Source of actual data: Barton and Scholz, 1995). 
OBSERVED FIELD DISTRIBUTION, OIL AND GAS, FRIO STRAIN EXPLORATION PLAY, TEXAS

Actual and Calculated to 1960 and 1970 and predicted to 1985 with VSD Model

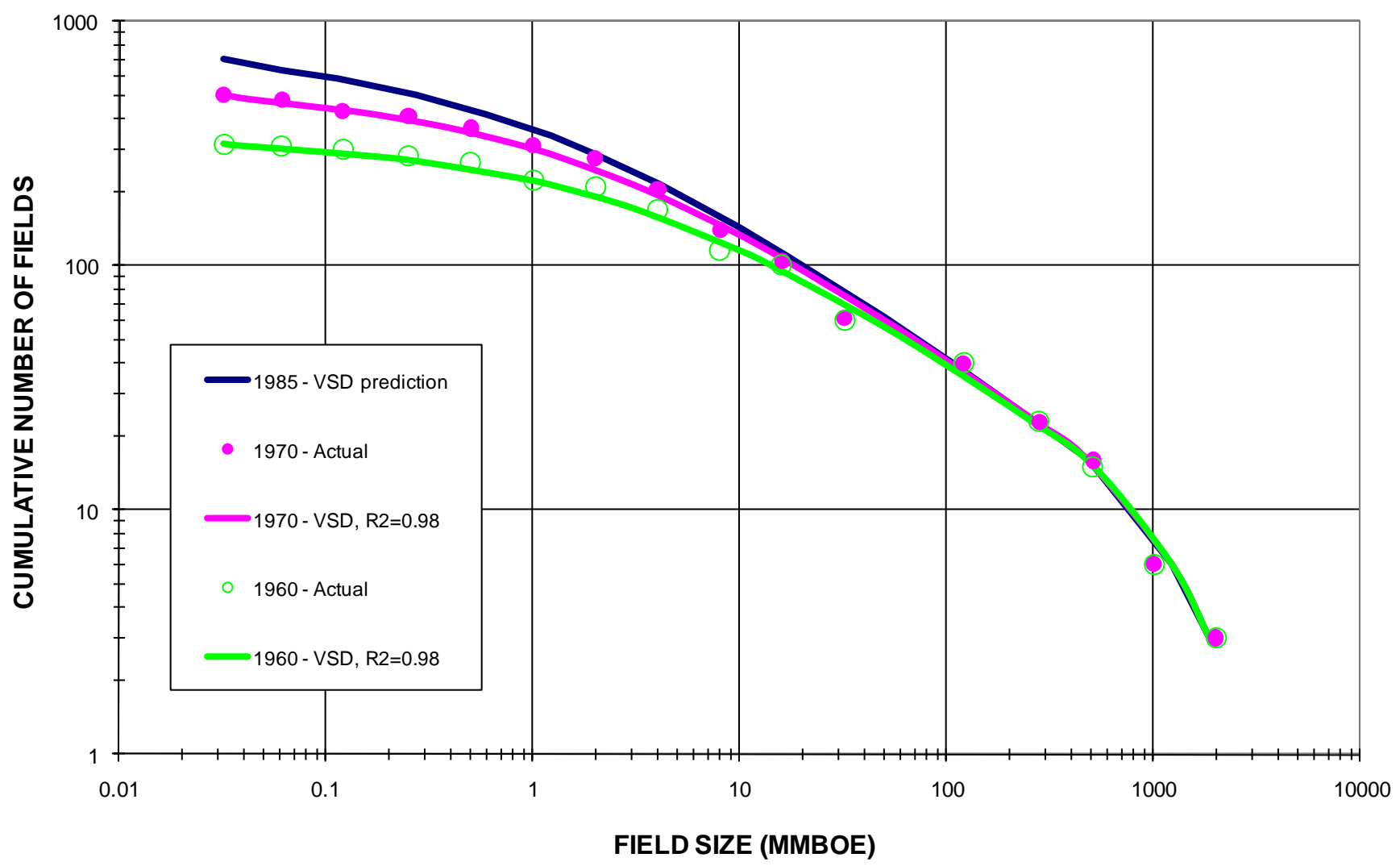

Fig. 15 Log-log plot by time segments of cumulative frequency of oil and gas fields vs. field size and best fit obtained with the VSD model to 1960 and 1970 (Source of actual data: Barton and Scholz, 1995). Also shown is the predicted distribution of the VSD to 1985. 


\section{OBSERVED FIELD DISTRIBUTION, OIL AND GAS, FRIO STRAIN EXPLORATION PLAY, TEXAS Actual and Calculated to 1960,1970 and 1985 with VSD Model}

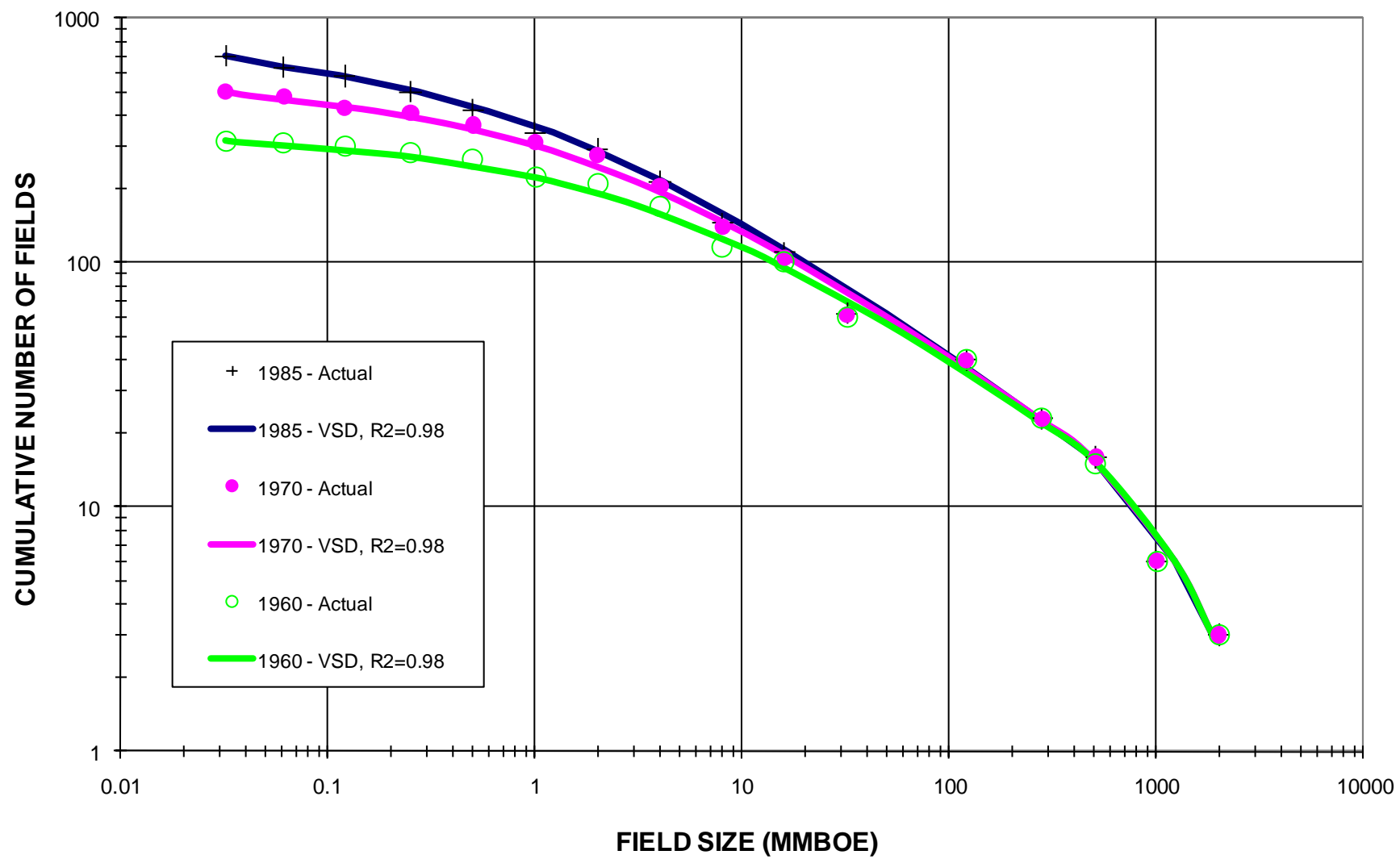

Fig. 16 Log-log plot by time segments of cumulative frequency of oil and gas fields vs. field size and best fits obtained with the VSD model for 1960, 1970 and 1985. The VSD fits the USGS data with coefficients of determination $\left(\mathrm{R}^{2}\right)$ equal to 0.98 (Source of actual data: Barton and Scholz, 1995). 


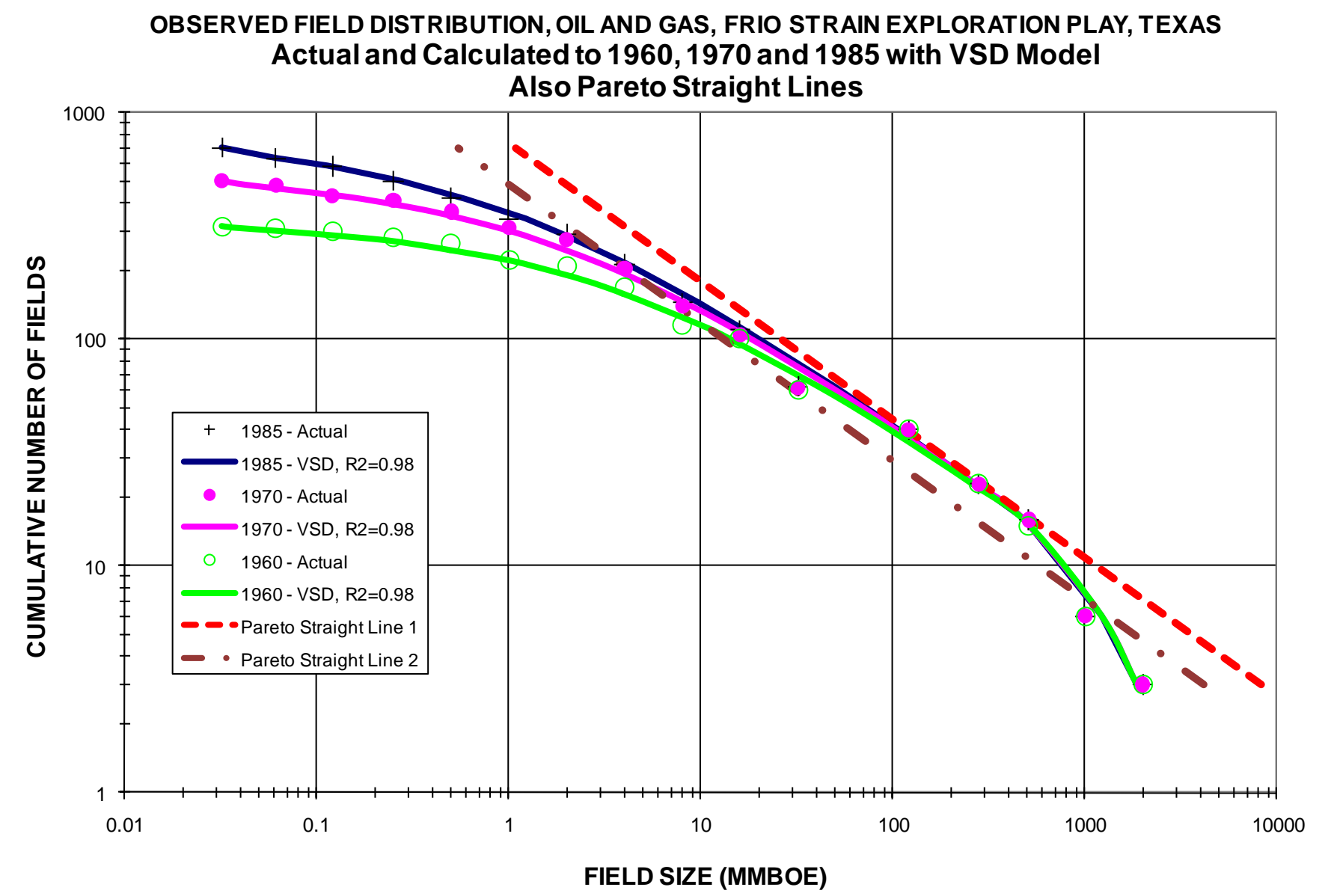

Fig. 17 Log-log plot by time segments of cumulative frequency of oil and gas fields vs. field size and best fits obtained with the VSD model for 1960, 1970 and 1985. The VSD fits the USGS data with coefficients of determination $\left(\mathrm{R}^{2}\right)$ equal to 0.98 (Source of actual data: Barton and Scholz, 1995). Graph also includes Pareto straight lines for 2 different cases, neither of which are as accurate as the curves generated with the VSD model. 